Canadian

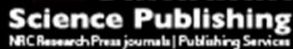

Canadian Geotechnical Journal Revue canadienne de géotechnique

\title{
Downhill Progressive Landslides in Long Natural Slopes. Triggering Agents and Landslide Phases modeled with a Finite Difference Method
}

\begin{tabular}{|r|l|}
\hline Journal: & Canadian Geotechnical Journal \\
\hline Manuscript ID & cgj-2015-0651.R1 \\
\hline Manuscript Type: & Article \\
\hline Date Submitted by the Author: & $29-$ Apr-2016 \\
\hline Complete List of Authors: & $\begin{array}{l}\text { Bernander, Stig; Luleå University of Technology, Civil, Environmental and } \\
\text { Natural Resources Engineering; Private Consultant, Tegelformsgatan 11, } \\
\text { SE 431 36 } \\
\text { Kullingsjö, Anders; Skanska Sverige, Skanska Teknik; Chalmers University } \\
\text { of Technology, Soil Mechanics and Foundation Engineering } \\
\text { Gylland, Anders; Multiconsult, Geoengineering; Norwegian University of } \\
\text { Science and Technology, Geotechnical Engineering } \\
\text { Bengtsson, Per-Evert; Swedish Geotechnical Institute; PEB Geoteknik AB, } \\
\text { per-evert@pebgeoteknik.se } \\
\text { Knutsson, Sven; Lulea University of Technology, Lulea, Sweden, } \\
\text { Department of Civil, Environmental and Natural Resources Engineering; } \\
\text { Pusch, Roland; Luleå University of Technology, Department of Civil, } \\
\text { Environmental and Natural Resources Engineering } \\
\text { Olofsson, Jan; Skanska Sweden, Skanska Teknik } \\
\text { Elfgren, Lennart; Luleå University of Technology, Civil, Environmental and } \\
\text { Natural Resources Engineering }\end{array}$ \\
\hline Keyword: & $\begin{array}{l}\text { Landslides in long natural slopes, Progressive failure in different phases, } \\
\text { Effects of time and rate of loading, Massive spread over level ground, Finite } \\
\text { difference method of analysis }\end{array}$ \\
\hline
\end{tabular}

\section{SCHOLARONE \\ Manuscripts}




\title{
Downhill progressive landslides in long natural slopes. Triggering agents and landslide phases modeled with a finite difference method.
}

\author{
Stig Bernander, Anders Kullingsjö, Anders S. Gylland, Per-Evert Bengtsson, \\ Sven Knutsson, Roland Pusch, Jan Olofsson, and Lennart Elfgren
}

Stig Bernander, Department of Civil, Environmental and Natural Resources Engineering, Luleå University of Technology, SE-97187 Luleå, Sweden; stig.bernander@telia.com

Anders Kullingsjö, Skanska Sverige, Johan på Gårdas gata 5, SE-405 18 Göteborg, Sweden; and Chalmers University of Technology, GeoEngineering, SE-412 96 Göteborg, Sweden; anders.kullingsjo@skanska.se

Anders S. Gylland, Multiconsult, Sluppen 15, NO-7037 Trondheim, Norway and Norwegian University of Science and Technology, Geotechnical Engineering, NTNU, NO-7491 Trondheim, Norway; anders.gylland@multiconsult.no

Per-Evert Bengtsson, Swedish Geotechnical Institute, Olaus Magnus väg 35, SE-581 93 Linköping, Sweden; per-evert.bengtsson@swedgeo.se

Sven Knutsson, Department of Civil, Environmental and Natural Resources Engineering, Luleå University of Technology, SE-97187 Luleå, Sweden; sven.knutsson@1tu.se

Roland Pusch, Department of Civil, Environmental and Natural Resources Engineering, Luleå University of Technology, SE-97187 Luleå, Sweden; drawrite.se@gmail.com

Jan Olofsson, Skanska Sverige, Johan på Gårdas gata 5, SE-405 18 Göteborg, Sweden; jan.olofsson@skanska.se

Lennart Elfgren, Department of Civil, Environmental and Natural Resources Engineering, Luleå University of Technology, SE-97187 Luleå, Sweden; lennart.elfgren@1tu.se

Corresponding Author: Lennart Elfgren, Department of Civil, Environmental and Natural Resources Engineering, Luleå University of Technology, SE-97187 Luleå, Sweden; lennart.elfgren@1tu.se, tel +46920493660, +46706 891360 (cell) 


\section{Abstract}

A large landslide in Tuve (Gothenburg, Sweden 1977) initiated the development of a model for slope stability analysis taking the deformation-softening of soft sensitive clays into consideration. The model studies triggering agents and five phases in progressive slope failure are identified: (1) in-situ, (2) disturbance, (3) unstable 'dynamic', (4) transitory (or permanent) equilibrium, and (5) 'global' failure. The clay resistance in these phases may differ widely; mostly due to different rates of loading.

Two time dependent failure criteria are defined: (i) the triggering load condition in the disturbance Phase (2), and (ii) the transitory equilibrium in Phase (4), indicating whether minor downhill displacements or a veritable landslide catastrophe will occur. The analysis explains why downhill landslides tend to spread over vast areas of almost horizontal ground further down-slope. The model has been applied to landslides in Scandinavia and Canada. Three case studies are briefly discussed.

The model is a finite difference approach, where local downhill deformations caused by normal forces is maintained compatible with deviatory shear deformations above the potential (or the established) failure surface. Software and an easy-to-use spreadsheet are introduced as well as recent developments.

\section{Keywords}

Landslides in long natural slopes, Progressive failure in different phases, Triggering agents, Effects of time and rate of loading, Two main failure criteria, Invalidity of one singular static load condition, Massive spread over level ground, Finite difference method of analysis.

\section{Technical Paper to the Canadian Geotechnical Journal}

Text revised: January 29, 2016; April 27, 2016 


\section{Introduction}

Disastrous landslides occur time and time again in long slopes of deformation-softening clays in Canada, Scandinavia and other areas with glacial and post glacial sediments emerging from regressing seas after the glacial period. In these areas the clay may be extremely sensitive and thus liquefy when remoulded (quick clays). In consolidated undrained triaxial tests and direct shear tests the clays exhibit a peak strength after which the soil structure collapses leading to increased pore water pressure and a corresponding reduction in effective stress.

Many slides have until the last years mostly not been explained satisfactorily by post-slide investigations when applying the classic limit equilibrium method based on perfectly plastic clay response. Instead, a strain/deformation-softening approach is required. The development of a method based on such conditions will be discussed here.

Factors triggering landslides are often related to construction work or river erosion. In sensitive clays, a minor instability can progress (downwards) or retrogress (upwards) depending on where the instability is triggered. In both cases, massive volumes of clay may finally be involved.

Early aspects on various types of progressive failure, mostly in highly over-consolidated clays, have among other been treated by Terzaghi and Peck (1948), Kjellman (1955), Skempton, (1964), Bjerrum (1967), Christian and Whitman (1969), Bishop (1971), Flodin and Broms (1981), Chen et al. (1997) and Leroueil (2001).. The first author of this paper began studying the effects of highly strain-softening soils after the landslide at Tuve in Göteborg that occurred in 1977, Bernander (1978). He has later published conference papers and reports on downhill progressive slope failures, Bernander $(1985,2000,2008,2011)$ and Bernander et al. (1981, 1984, 1985, 1989).

Today, progressive and retrogressive landslide failure has become a recognized phenomenon in highly deformation-softening soils. Research and development in this 
discipline of soil mechanics is now going on in several countries, notably in Australia,

Canada, Italy, Norway, Sweden and Switzerland. State of the Art reviews and recent progress

are reported in theses by Troncone (2005), Locat (2007, 2012), Thakur (2007), Quinn (2009), Saurer (2009) and Gylland (2012). Their work is also further developed in the workshop proceedings (L'Heureux et al.,2013), in papers by e.g. Locat et al. (2008, 2011, 2013, 2015), Gylland et al. (2014), Bonadies et al. (2014), Zhang et al. (2015) and in the editorial by Puzrin (2016). Focus is often on material properties and on numerical solutions of various kinds, e.g. finite element methods.

The current paper discusses how landslides in long slopes of deformation-softening clay can be modelled as a downhill progressive failure using a finite difference two-dimensional model. The description of the initial phases of a slide is similar to what is presented in many of the recent papers referred to above. But beyond this, the following cardinal issues are in focus in the following:

(a) How do we explain the fact that extensive landslides can be triggered by relatively insignificant local additional load effects?

(b) Is it, in the analysis, mandatory to consider the deformations in the entire highly sheared zone or is it merely sufficient to study those in a narrow shear band?

(c) Is it important to identify distinctly different phases in progressive landslides? How does the time affect the triggering loading conditions and further slide development?

(d) Can landslide hazard in sensitive clays be correctly predicted by only one singular failure criterion based on static loading such as e.g. the Plastic Limit Equilibrium Failure condition?

(e) Is it essential to differentiate between deformations in the zones of un-fractured clay and corresponding conditions subsequent to the formation of a failure surface or shear band? 
(f) How do we, in these landslides, explain the massive heave and plasticization over extensive areas of gently sloping or horizontal ground?

\section{Exemplification of the analysis of the initial phases of a downhill} progressive landslide

In order to illustrate the characteristics of a progressive failure, a simplified example is presented in Figures 1 - 3. Figure 1 represents a typical stress-strain relationship for clay with strain-softening behaviour. The curve can be described by the following set of parameters. The linear elastic limit is defined by the coordinates $\tau_{\mathrm{el}} / \gamma_{\mathrm{el}}$ and the peak resistance by $s / \gamma_{\mathrm{f}}$. Beyond the peak stress, $\tau_{\max }=s$, the resistance in the failure surface is taken to be related to the slip $\delta$ in this plane. This also defines the change from Stage I (increasing stresses) to Stage II (softening). The deformation $\delta_{R}$ defines a condition when the abating shear resistance along the slip plane attains an ultimate value $s_{R}$. The values of the parameters may vary with depth and time and will be discussed later. The values given in Figure 1 will be used in the following introductory example, adapted from Bernander (2011).

Figure 2 shows a slope, where a long portion has constant inclination $\beta$ and invariable depth $H$ to the potential failure surface. This simplistic geometry is just chosen in order to facilitate the understanding of the main issues involved. Yet, the current finite difference method can deal with arbitrary geometry and varying soil strength characteristics.

Figures 2 and 3 illustrate the effects of a triggering load $N_{q}$, which in the current case is caused by an uphill load $q$. The top part of Figure 2 illustrates the geometry, the middle part illustrates the shear stress, $\tau$, and the bottom part illustrates the additional earth pressure $N$ above the potential (or the developing) failure plane. The coordinate $L$ (downwards) has the value $L=0$ where the load $N_{\mathrm{q}}$ is entered. The coordinate $x$ (in the opposite direction of $L$ ) has the value $x=0$ at the location, where the effects of the load $N_{q}$ are practically zero. This is the 
location where the additional earth pressure $N_{\mathrm{x}}$, the displacement $\delta_{\mathrm{x}}$ and the resulting shear stress $\tau_{x, z}-\tau_{o}$ are negligible. Here $\tau_{x, z}$ is the shear stress as a function of the coordinates $x$ and $z$ and $\tau_{o}$ is the in situ shear stress (which also may vary with $x$ and $z$ ). In the example the in situ stress $\tau_{o}$ relates to the failure plane.

The development of the initial phases of a progressive failure is illustrated by five moments $(\mathrm{a} \rightarrow \mathrm{e})$ related to gradually increasing values of the force $N_{q}$. Corresponding values are given for the shear stress $\tau_{x}$ (for $z=0$ ) along the potential failure plane, as well as the values of the length $x=L$, signifying the distance over which the load $N_{q}$ has any appreciable effect. The corresponding downhill displacement $\delta_{\mathrm{x}}$ at the point of loading is given in Figure 3, where also the first three phases of the landslide are illustrated. The total downslope earth pressure $E$ $=E_{o}+N$ is introduced as the sum of the original in situ force $E_{o}$ and the additional force $N$ caused by the applied load $q$.

In the following the different phases will be outlined.

\section{Significant phases of a downhill progressive landslide}

\section{Phase 1 - In situ condition}

In the in-situ condition, i.e. Moment $\boldsymbol{a}$ in Figures 2 and 3, the load $N_{q}=N_{a}=0$ and the shear stress along the potential failure surface is $\tau_{0}$. The in situ earth pressure above the potential shear surface is $E_{o}(x)$ and is related to the dead load of the clay and the relation between horizontal and vertical stresses. Normally effective stresses are considered in this phase. The deformation $\delta_{\mathrm{a}}=0$.

\section{Phase 2 - Disturbance phase}

In Phase 2 an additional - gradually increasing - vertical load $q$ is applied near the top of the slope inducing an earth pressure increase corresponding to a force $N_{q}$ (above the shear 
surface). The resulting earth pressure distribution down the slope is $E(x)=E_{o}(x)+N(x)$, see

(Figure 2 bottom). From now on total stresses usually have to be considered. Under continued loading, the peak shear resistance will be attained at the point of loading, see Figure

2(middle). This defines Moment $\boldsymbol{b}$, where $\tau=\tau_{\max }=s$ and $N_{q}=N_{b}$ for $x=L_{\mathrm{b}}$ (Figure 2 bottom) and the deformation is $\delta_{\mathrm{b}}$ (Figure 3).

Further increase of $N_{q}$, makes the shear stress $\tau_{\mathrm{x}}$ abate due to strain-softening (Figure 2 middle). When this stress attains the original in situ value $\tau_{\mathrm{x}}=\tau_{\mathrm{o}}$ at $x=L_{\mathrm{c}}$ we have reached Moment $\boldsymbol{c}$ and all available shear resistance exceeding $\tau_{\mathrm{o}}$ is exploited, implying that $N_{q}$ reaches its critical peak value $\boldsymbol{N}_{\boldsymbol{q}}=\boldsymbol{N}_{\text {crit }}$ (Figure 2 bottom and 3). This is the first criterion for local failure and landslide initiation. The corresponding effective influential length $L_{c}$ is denoted $\boldsymbol{L}_{\text {crit }}$ and the displacement at the point of load application is $\delta=\delta_{\mathrm{c}}=\boldsymbol{\delta}_{\text {crit }}$ (Figure 3) corresponding to $\delta_{\mathrm{R}}$ (minus the in situ deformation due to $\tau_{\mathrm{o}}$ in Figure 1 . Moment c marks the end of Phase 2. The possible sustained earth compression force $N$ will now start to decrease as $\tau$ gets lower than $\tau_{o}$ signifying a changeover from a static situation to an unbalanced, virtually dynamic condition.

For a downhill progressive failure, the triggering load often consists of fills, as in Figure 4. There also the deformation profiles along the slope are shown. A shear slip is indicated for $\tau<\tau_{o}$ between moments $\mathrm{c}$ and $\mathrm{d}$ in Figure 2. The load from fills may significantly be accentuated by the effects of water saturation, explaining the fact that landslides often coincide with long spells of rain during which also hydraulic pressures in existing cracks above the ground water table may exert pressures in downhill direction. Other common triggering load effects are rock blasting, pile driving and vibratory activity.

Apart from inherent soil brittleness, the following factors may influence failure in Phase 2: 
- The slope geometry and the profile of the potential slip surface - here named 'geometric brittleness';

- Nature and distribution of the applied incremental load or disturbance effect;

- Location and time-span of the agents initiating failure. Rate of load application;

- Drainage conditions in the impending failure zone;

- Hydrological conditions and hydrological history.

\section{Phase 3 - Unstable 'dynamic' state}

When the load $N_{q}=N_{\text {crit }}$ is exceeded, static equilibrium is no longer possible - unless the additional loading effect is genuinely deformation-controlled and its value can be momentarily reduced, e.g. as may be the case when piling with soil-displacing elements. Otherwise, the slide now enters a virtually dynamic phase, in which unbalanced upslope forces are transmitted to more stable, less inclining ground further down the slope.

Moment d represents a condition within this dynamic phase, when the stress $\tau$ for $x=L_{d}$ reaches the residual shear resistance $s_{R}$ (Figure 2) and the allowable load $N_{q}$ at the application point is reduced to $N_{\mathrm{d}}$ (Figures 2 and 3).

Moment e represents another specific situation in Phase 3, when the total passive resistance force $E_{P}$ just balances the forces acting downhill. In Figure 2 (middle) this is illustrated by the area for which $\tau \geq \tau_{o}$ is equal to the area for which $\tau \leq \tau_{o}$ (shaded). The allowable load $N_{q}$ is now reduced to zero (Figure 2 and 3). The corresponding value of $L_{e}$ may be denoted $\boldsymbol{L}_{\text {instab }}$. From this point and on, the force $\mathrm{N}$ turns negative (Figure 2 bottom) and equilibrium in Phase 3 can no longer be maintained.

\section{Phase 4 - Transitory (or permanent) equilibrium}

In the course of the following dynamic process, the shear resistance along the developing failure plane is effectively reduced leading to massive earth pressure build-up further downslope in less sloping ground. Phase 4 represents a condition, in which the pressure build-up 
resulting from Phase 3 is permanently or temporarily balanced by passive resistance - i.e. $\left(E_{o}+N\right)_{\max } \leq E_{P}$. Phase 4 is exemplified in Figure 5 showing a situation, where a pressure amounting to $95 \%$ of passive Rankine resistance, acts at the foot of a steep slope. The stressdeformation relationship is slightly different from the one in Figure 1 and the short-term peak shear strength is, in this specific exemplification, assumed to be1,2 $s$ during this phase (short time stress tests are known to render higher peak stress values than those obtained in normal laboratory tests). The middle figure shows the shear stress $\tau$ for a case with $s_{R} / s=0,4$. The lower figure displays the resulting deformations and spreads for sensitivity ratios $s_{R} / s$ varying from 1,0 to 0,4 . The corresponding lengths $x=L_{p}$, of the integral shear zones required to balance the pressure at A, range between 120 and $240 \mathrm{~m}$, thus increasing as $s_{R} / s$ decreases. Provided the maximum value of $E$ stays less than the passive earth pressure resistance $E_{P}$, the slope will merely be subjected to moderate displacements and essentially remain stable. This is not an uncommon case and the outcome may be a minor local failure or moderate displacements of a few decimetres and cracking upslope. An example of this is the slide movement in 1977 at Rävekärr, see the case study below.

Analysis of Phase 4 is therefore of decisive significance, as this phase actually constitutes a measure of the potential extension of a downhill progressive landslide, and hence it's veritable degree of disaster. The ratio $E_{P} /\left(E_{o}+N\right)_{\max }<1$ in in_Phase 4 actually constitutes the second criterion for landslide formation.

\section{Phase 5 - Fully developed global failure}

Yet, as already implied, the actual landslide occurs if the pressure acting downhill in Phase 4 exceeds available passive resistance $E_{P}$. This condition is illustrated in Figure 6 for a slope with changing inclination giving the initial force $E_{\mathrm{o}}$ a local maximum. In the top of the figure the geometry of the slope is shown. In the middle of the figure the shear stress distribution is shown for two cases. In Case 1 the residual stress is $s_{\mathrm{R}}=15 \mathrm{kPa}$ and in Case 2 it is lower $s_{\mathrm{R}}=$ 
$10-15 \mathrm{kPa}$. In the bottom of the figure the variations of the earth pressure $E$ and the deformations $\delta$ are shown for the two cases.

Case 1 is a situation in Phase 4, where the passive resistance $E_{P}$ just balances the forces acting downhill $E_{\mathrm{o}}+N_{1=} E_{P}$, thus representing the mentioned critical boundary condition for a veritable landslide event. The length of the slope from the point of no load influence to the point with maximum shear stress is $x_{1}=141 \mathrm{~m}$ and the sum of the applied shear stresses is $N_{1}$ $=1200 \mathrm{kN} / \mathrm{m}$.

Case 2, on the other hand, illustrates an ongoing failure condition in Phase 5, in which static equilibrium no longer exists, i.e. $E_{\mathrm{o}}+N_{2}>E_{P}$, thus resulting in massive heave and downhill displacements. The length of the slope from the point of no load influence to the point with maximum shear stress is here longer than in Case $1, x_{2}=205 \mathrm{~m}$, due to a lower residual stress $s_{\mathrm{R}}$ and the resulting downhill forces are consequently greater, $N_{2}=1840 \mathrm{kN} / \mathrm{m}$, confer Figure 5.

Phase 5 may also include the effects of dynamic inertia forces. In this phase, the slope will reach its final post-slide state of equilibrium as illustrated in Figure 7. Due to softening of the clay along the failure surface, the resultant down-slope forces increase building up an earth pressure which may cause failure in a massive passive zone of disintegrated soil. Note that the soil between this disintegrated zone and the active zone at the origin of the slide may remain undisturbed except close to the failure surface.

It is here vital to be aware of the fact that the failure along the lengthy progressively formed failure zone with its extended shear band is - for reasons given below - of an entirely different nature than that of a passive failure condition in the soil mass:

(a) Firstly, the two failure phenomena are not even concurrent. Already before passive downslope resistance is fully attained, both the sheared zone (from $z=0$ to $z=\alpha H$ ) and the established shear failure plane (where $z=0$ ), that are related to the failure in Phase 3 will provided the depth to the slip surface is sufficient - have developed far beyond the foot of the 
slope. This implies that before passive failure along short inclined slip surfaces has even begun to form, there already exists an extensive shear failure zone (including shear band), where large deformations (often in terms of meters) and substantial deformation-softening have already taken place. (Cf Figures 5 and 7).

(b) In the transitory critical stage of progressive landslide formation, earth pressures will be subject to rapid growth resulting, temporarily, in higher peak shear strengths than those corresponding to standard laboratory testing, Graham et al (1983), Bernander et al. (1985). The passive resistance is thus likely to exceed standard evaluation of passive resistance implying that $E_{P}$ for a time $t=\Delta t$ may well transiently be greater than the long term value of $E_{P}(t=\infty)$ over the entire potential spread area of the landslide. This condition has been corroborated by Gylland and Jostad (2010).

(c) Yet, even considering that passive failure may begin locally at the peak value of $E(\mathrm{x})=$ $E_{o}(x)+N(x)$, the pressure distribution as defined by Phase 4 will still not be affected significantly. Deformations and deformation-softening in the fully developed failure zone are massive in the current stage. This means that the balance between forces acting down-slope and stabilizing resistance then constitutes an immense force, the temporary magnitude of which is practically independent of incipient heave in the soil mass. This implies in turn that developing resilience in the passive zone to be has little effect on the earth pressure distribution as defined in Phase 4 or on the ensuing general failure conditions.

The points (a), (b) and (c) above explain the heave and the enormous spread over horizontal or gently sloping ground that is so typical of downhill progressive landslides.

\section{Conclusion}

It is thus evident that progressive landslides consist of a series of different events with mutually varying time spans, rates of loading, drainage conditions - and therefore also radically different constitutive response of the sensitive clay in the different phases of failure. 
Progressive landslides cannot therefore be correctly studied and predicted only on the basis of a singular case of static loading.

\section{Failure conditions}

In downhill progressive landslides, there are, as indicated above, two decisive static failure conditions, for which the corresponding safety factors have to be defined:

(i) The critical disturbing load condition at the end of Phase 2, capable of triggering a landslide has a safety factor of

$$
F_{s}{ }^{I}=N_{c r i t} / N_{q} \geq 1
$$

Here $N_{q}$ is the local additional load. The triggering value of the load $N_{q}$ is $N_{\mathrm{c}}=N_{\text {max }}=N_{\text {crit }}$ with its related values of $\delta_{c}=\delta_{L}=\delta_{\text {crit }}$ and $x_{c}=L_{c}=L_{\text {crit }}$, see Figure 2 .

(ii) A transitory or in some cases permanent state of static equilibrium in Phase 4 subsequent to the redistribution of earth pressures caused by the triggering load. This criterion defines the safety factor for the global failure condition indicating whether a veritable landslide will develop or not:

$$
\boldsymbol{F}_{\boldsymbol{s}}^{I I}=\boldsymbol{E}_{\text {passive }} / \boldsymbol{E}_{\max } \geq 1
$$

Here $E_{\max }$ denotes the maximum earth pressure resulting from the virtually dynamic pressure redistribution in Phase 3. In Phase 4 the relationship $E_{\text {passive }} / E_{\text {max }}$ may be bigger or equal to 1 but if it turns less than 1 the slide will enter Phase 5 and a global failure will occur.

The two criteria were proposed by Bernander et al $(1981,1985)$ and in this journal by Locat et al. (2011).

\section{Basics of the finite difference model}

The failure modes discussed above can be modeled with a finite difference method (FDM), Bernander (1985, 2000, 2008 and 2011) and Bernander et al. (1984, 1985, 1989). The method 
is illustrated in the Appendix (Figure A1 by the analysis of a long slope with variable inclination $\beta$ and depth $H$ to the firm bottom, whereas Figure 8 shows the analysis applied to a simple case with constant inclination $\beta$ and depth $H$. The slope is initially in equilibrium and the in situ shear stresses at the potential failure plane are $\tau_{o}$. The objective of the simplified analysis is to demonstrate the effects of an additional local load upslope.

The integration process starts at a point $(x=0)$ further down the slope, where the influence of the additional load $N_{\mathrm{q}}$ is negligible, by choosing an initial shear stress increment at the potential failure plane $\boldsymbol{\Delta} \boldsymbol{\tau}$ at a distance $x=\boldsymbol{\Delta x}$. The corresponding increase of the normal force $N$ and the associated downhill axial displacement $\delta(N)$ may then directly be determined.

In the analysis the mean downhill deformation in each element caused by normal forces is maintained compatible with the deformation generated in the lower portion of the element by shear stresses in the potential (Stage I or the established) shear failure surface (Stage II). By selecting new values of $\boldsymbol{\Delta} \tau$, this equation can readily be adjusted so that the compatibility criterion is satisfied, i.e.

$\delta_{x}(\tau)=\delta_{x}(N)$

The process is further presented in the Appendix.

Varying geometry, different constitutive relationships and time spans can in this context be dealt with in a computer program originally developed in 1984.

In slopes with constant inclination and depth to the slip surface, the analysis can readily be carried out in an easy-to-use spread sheet (Excel). A simplified version of this is presented in Rehnström (2013).

The advantage of the finite difference methodology (FDM) as outlined above relative to more advanced numerical simulations using e.g. the finite element method (Jostad et al 2013), the material point method (Zabala and Alonso 2011) or X-FEM (Thakur and Septanika 2008) 
is that one avoids all issues of numerical instability, non-uniqueness of the solution, strain localization, regularization techniques and internal length parameters. The use and interpretation of the result is hence more transparent and available for being evaluated correctly by the user.

\section{Case studies}

\section{Surte landslide}

The Surte landslide on the bank of the Göta River some $15 \mathrm{~km}$ North ofGothenburg, Sweden, took place soon after 8 a.m. on September 29, 1950. The main slide, involving some 24 hectares of ground, swept away 31 family houses and 10 outhouse units. Due to the hour most residents already having gone to work elsewhere - the death toll was limited to one person.

The south-bound branch of the Göta River, which is navigable for heavy shipping transport, was blocked for two months. The north-bound railway and highway were displaced varying distances up to $150 \mathrm{~m}$, blocking road and railway traffic for 10 and 19 days respectively. Transportation and industry incurred serious damage.

Figures 9 and 10 are aerial photos of the slide area. Figure 11 shows a plan and a longitudinal section of the slide. The inclination in the steepest uphill part was about $5 \rightarrow 7: 100$ and the mean value further downhill only 2:100. The quick clay properties will be discussed below. The actual slide event was observed by a number of people within and outside the slide area. One of them summed up his impressions as follows (Caldenius and Lundström, 1956):

"The whole ground was moving rather slowly at a speed that can approximately be compared to that of the Bohus ferry. (Estimated speed a few meters per second.) The movement did not proceed at the same speed all the time - the speed increased progressively 
and the movement finally ceased when the ground piled up against the opposite side of the river. Then the ground rose and folded. However, folding had already begun during the first stage of the movement. House No 13 toppled very slowly when the slide was approaching the opposite side of the river. Water and clay were lifted very high. Cracks of various sizes were formed during the course of the slide. At first, the ground moved straight down towards the river but further down the slide widened, while the main part of the ground continued straight ahead."

Another important witness, standing in her kitchen and facing south, told among the following: "She first noticed that a pile driving machine and the ground around it began to subside and that the men engaged in pile driving started to run away. Then she observed that the houses beyond were also moving. ....The pile driving machine did not topple until the last stage of the movement. A large number of cracks formed in the ground. The movement was wavelike and smooth. The houses seemed to sail along. “

With reference to Figures 1 and 12, the characteristic parameters in Table 1 have been used in this study. Different constitutive relationships are used in the different phases of the landslide and the likely stress-deformation relationships are shown for (a) the in situ condition, (b) the disturbance condition and (c) the global failure. In the table, $s=\tau_{\max }$, denotes the peak shear strength and $s_{\infty}$ is the maximum shear resistance under long term conditions. $G$ is the elastic shear modulus and $E=2(1+v) G$ is the elastic modulus of elasticity. Sensitivity studies show that variations of the here assumed properties do not change the outcome of the analysis in a decisive way, Bernander (2011).

In phase I, see Table 1, the available shear strengths in the steepest part of the slope do not match an in situ shear condition based solely on weight and slope inclination. According to the analysis, this stress difference corresponds to a force $N_{\mathrm{o}}=138 \mathrm{kN} / \mathrm{m}$ implying that already in the in situ condition, the soil masses were to some extent balanced by elevated 
earth pressures in less inclined ground further down the slope (comparable to Moment $\boldsymbol{b}$ in Figure 2).

Two disturbance conditions are studied in Phase 2: (a) one which is force induced with a critical additional load $N_{c r}=192 \mathrm{kN} / \mathrm{m}$ and (b) one which is deformation induced with a critical value of deformation of $\delta_{\text {instab }}=0.29 \mathrm{~m}$ (corresponding to $\delta_{e}$ in Figure 3 ). The force disturbance would correspond to a rapidly applied overload of only $q_{c r} \approx 192 / 18=10,7 \mathrm{kN} / \mathrm{m}^{2}$ extending $18 \mathrm{~m}$ up-slope of Point $\mathrm{P}$ in Figure 11.

However, the Surte slide was probably triggered by ongoing pile driving for the foundation of a family house at the time of the slide event. The number of piles in the foundation was not quite sufficient to generate a down-slope displacement of the magnitude of $\delta_{\text {instab }}=0.29 \mathrm{~m}$ but it is very likely that the piling activities also locally induced high pore water pressures and loss of shear strength in possible local seams of coarser moraine out-wash in the clay formation. Such coarse strata commonly intermix with clay sediments in the vicinity of the ancient shores of the regressing post-glacial seas. A pore pressure rise of some $2 \mathrm{~m}$ would have been enough to initiate a failure, Bernander (2011). Significantly higher excess pore water pressures than $2 \mathrm{kN} / \mathrm{m}^{2}$ are often observed during piling operations.

The global failure condition illustrated in Figure 13 represents the situation at the end of the progressive Phase 3, in which unbalanced forces in the steeper parts of the slope have been transferred further down-slope, resulting in massive build-up of earth pressures (Phase 4) in more level ground. Calculated earth pressures $E$, ground surface elevation, shear stresses $\tau$ and displacements $\delta$ along the slip surface, are shown in the top, middle and bottom parts of the figure respectively. The length over which the passive Rankine resistance $E_{\text {Rankine }}$ is exceeded by the resulting maximum earth pressure $E_{\max }$ is $L_{E>E(\text { Rankine })}=320 \mathrm{~m}$.

It should be observed that the earth pressures in Figure 13 are calculated on the assumption that the potentially sliding soil volume transiently retains its geometrical shape before possible disintegration in passive failure. This is justified because the slip surface under the 
valley floor is fully developed far beyond the foot of the slope already in Phase 4. In Figure 13 this distance is more than $500 \mathrm{~m}$ prior to the potential final break-down of the passive zone in Phase 5 and is therefore not concurrent with the final dramatic event constituting the actual landslide.

The analysis of the Surte slide highlights how a local, seemingly trivial disturbance in a vulnerable part of the slope, had the potential of developing into a great disaster, massively destabilizing about $240000 \mathrm{~m}^{2}$ of ground that had remained stable for thousands of years. And yet, hypothetically, the slope may have remained stable to this day if the piling job had not taken place, or if it had been carried out in a different way.

\section{Tuve landslide}

The landslide in Tuve, a community in North Gothenburg, Sweden, took place on the $30^{\text {th }}$ of November, 1977, just after four o'clock in the afternoon - i.e. at a time that must have reduced the death toll significantly since people had not yet returned from work or from school. In all, the slide resulted in nine deaths, the total destruction of 65 family houses and a drastic change of the topography of some $270000 \mathrm{~m}^{2}$ of ground. Settlements in the active zone of about $10 \mathrm{~m}$ and horizontal displacements up to $200 \mathrm{~m}$ were recorded. Upheaval in the passive zone of about $5 \mathrm{~m}$ over a distance of some $300 \mathrm{~m}$ was noted, see Figures 14 and 15 , Larsson and Jansson (1982).

Two main phases could be identified, namely an initial slide event encompassing the ground east of line B-B in Figure 15 and a secondary retrogressive stage covering the area west of line B-B. The initial slide is presumed to having been triggered by local instability in the steepest portions of the slope, i.e. near and up-slope of the Tuve Church road (running diagonally from SE to NW in Figure 15). 
The characteristic parameters in Table 2 have been used as input in this study. The total height of the slope is less than $20 \mathrm{~m}$ with an inclination in the steepest part of about 5:100 and further downhill only 2:100. The clay properties are discussed below. In phase I, available shear strengths do not match the shear stresses in the steepest part of the slope as was the case in the Surte slide. This corresponds to a force $N_{\mathrm{o}}=671 \mathrm{kN} / \mathrm{m}$ and implies that already in the in situ condition, the soil masses were shored up by incremental earth pressure in less inclined ground further down the slope. Because of this condition, the relationship between horizontal and vertical stresses $K_{o}=\sigma_{h} / \sigma_{v}$ increases from 0.55 to maximum 0.64 along the slope. It also implies that the length over which shear stresses and deformations can be induced by local load effects $N_{q}$ is limited.

The vital consequence of this is that, due to the fact that the deformations related to $N_{q}=N_{c r}$ in this case do not materialize beyond the distance of $L_{c r}=91.2 \mathrm{~m}$ down-slope of the load, passive resistance there cannot be utilized for balancing the additional local load $N_{c r}$, even in the state of impending progressive failure. This applies in particular to an extensive slope such as the one in Tuve, measuring at least 300 meters, and where the soils were very sensitive in the upper parts. According to Table 2, the critical load $N_{c r}$, sufficient to initiate local failure in the steepest part of the slope, only amounts to $75.8 \mathrm{kN} / \mathrm{m}$. Assuming fully un-drained conditions in the disturbance phase the value of $N_{c r}$ merely corresponds to a distributed load on the ground surface $q_{c r}$ of about $75.8 / 17 \approx 4.5 \mathrm{kN} / \mathrm{m}^{2}$ (with a premised extension of the load of $17 \mathrm{~m})$,

As in the Surte case study, variations of the parameters do not change the outcome of the analysis in a decisive way, Bernander (2011).

Figure 16 displays the calculated earth pressure distribution (top), shear stresses (middle), slope geometry and location of the slip surface (bottom). The figure represents the situation at the end of the progressive redistribution in Phase 3, i.e. at the critical transitory condition in Phase 4 that is bound to develop into Phase 5. 
A dynamic analysis of the Tuve landslide using a schematic geometry has been performed with step by step numerical calculations in the time domain based on progressive failure development and Newton's laws of motion, Bernander and Gustås (1984). The time interval between the discrete steps in the computation was about 1 second. In Figure 17 elevations and shear stress distributions are illustrated for three phases from a sequence of results: (a) Phase 3, unstable 'dynamic', (b) Phase 4, transitory equilibrium, and (c) Phase 5, fully developed global failure. In the elevations, increasing earth pressure intensities are illustrated with shades of yellow $\rightarrow$ green $\rightarrow$ dark green $\rightarrow$ black, where black indicates that passive Rankine pressure is exceeded. In the stress diagrams the red color indicates from right to left: increasing stresses $\tau$, peak stress $s$, and the effects of deformation softening down to the residual stress $s_{R}$. The stresses marked in yellow color represent the balance between the effects of downhill forces and the residual shear resistance. According to the calculations, the time to failure is about 22 seconds. However, it is conceivable that, in reality, time dependent fracture and disintegration processes prolong the different phases of the slide.

The progressive failure analysis indicates that the upper part of the slope was extremely vulnerable to additional short-term loading and unprecedented disturbance related to human activity of various kinds. The analysis also provides a logical and quantitatively consistent explanation of the vast spread of the slide over almost horizontal ground. Furthermore, the analysis also highlights the fact that landslide displacements in sensitive clay are not confined to its directly visible topographical appearance.

The causes of the Tuve slide are probably local disturbances generated by high ground water pressures due to prolonged precipitation in combination with the effects of additional load from a road embankment applied a few years before at the Tuve Churh Road. 


\section{Rävekärr slide movement}

The slide took place in 1971 at Rävekärr, some $8 \mathrm{~km}$ South of Gothenburg in the gently sloping ground of a side valley opening out into the Mölndal River valley. Figure 18 shows a plan and a representative section of the $550 \mathrm{~m}$ wide slide area. The valley consists of soft normally consolidated very sensitive clay that below the dry crust has a strength of about $\mathrm{s}=$ $(10$ to $15+\gamma+\mathrm{z}) \mathrm{kN} / \mathrm{m}^{2}$ The inclination at the crack where the slide movement started was about 5:100 and grew less further down the valley,

A minor piling project for a family house had been started. When the sixth pile was being driven a crack in the ground suddenly appeared. The crack propagated at a speed, judged by an eyewitness to be about the pace of a running person $(\approx 5 \mathrm{~m} / \mathrm{s})$. It halted some $130 \mathrm{~m}$ northwards against an outcrop of firm ground. In the opposite direction, the crack in the ground passed through an area of family housing following the contour lines of the slope and came to a stop some $420 \mathrm{~m}$ from where it had started (Löfquist 1973).

The final width of the crack and the related vertical off-set due to local active failure was only 0.2 to $0.3 \mathrm{~m}$. The total area, subject to documented down-slope displacement in this order of magnitude, was about $150000 \mathrm{~m}^{2}$. Slip surfaces were documented at depths of $5-7 \mathrm{~m}$ in the upper part of the slide and angular deformations were recorded at $13 \mathrm{~m}$ and $33 \mathrm{~m}$ depth in the lower parts of the valley.

Although the ground down-slope of the crack was somewhat displaced, no passive zone with associated heave was observed, implying that the crack originated from deformations related to the redistribution of stresses and earth pressures in accordance with the dynamic phase (Phase 3) of a progressive failure. Before the slide event, elevated ground up-slope had essentially been stabilized by the in situ shear forces. The redistribution in Phase 3 meant that the up-slope loss of shear strength was compensated by a corresponding build-up of earth pressures in the down-slope area. Hence, the documented displacements forming the slide relate to this transfer of forces of a virtually dynamic nature. 
The slide at Rävekärr represents a case, where the earth pressure increase in the 'post progressive' state of equilibrium (Phase 4) remained smaller than the passive resistance at the foot of the slope. This specific condition, i.e. $\left(E_{o}+N\right)_{\max }<E_{P}$, was manifestly confirmed byroutine progressive failure analysis. .

The slide movement at Rävekärr indicates that the time range for progressive failure of this type to take place can be a matter of tens of seconds or a few minutes.

It may be concluded that the ground movement at Rävekärr canbe classified as an 'unfinished landslide' where, owing to the low slope gradient, the depth of the soil in the triggering location and/or to moderate sensitivity of the soil further down-slope, the progressive failure did not terminate in massive upheaval of the passive failure zone. There are many examples of the described kind of slide movement in parts of the Swedish West coast, although seldom being as extensive as the one in Rävekärr.

\section{Landslide prediction - examples and comments}

A vital question is the way critical portions of a slope will respond to additional loading or disturbance. The 'time horizon' for a disturbance is usually expressed in terms of days, weeks or months, whereas the slope itself has existed for hundreds or thousands of years under diverse extreme climatic conditions. So, what is likely to ensue? Will local instability just result in minor movements and cracking in the up-slope 'active zone'-i.e. a lasting equilibrium in Phase 2 or Phase 4 - or will it terminate in a disastrous landslide (Phase 5) with heave and spread over vast areas?

To begin with, an estimate of the in situ stress conditions has to be defined. Often the horizontal earth pressure can be estimated as $E_{o} \approx K_{o} \cdot 0,5 \rho g H^{2}$ with $K_{o}$ being the ratio between horizontal and vertical in situ stresses along the slope $\left(K_{o}=\sigma_{h} / \sigma_{v}\right)$. The $K_{o}$-values may be chosen empirically on the basis of past experience. However, they may also be 
calculated on the basis of a reasonable long term stress/deformation relationship - the basic idea being that creep in a slope can be treated as an extremely slow progressive failure process. In the absence of specific tests related to creep, long term shear strength and perfect plastic properties in the soil can be applied in this context. The input value of $K_{o}$ may typically vary between 0.5 and 1.0 in different parts of the slope. Possible inaccuracies in the first assessment of the $K_{o}$-values may subsequently be adjusted by repeating the analysis on the basis of the results of the foregoing assessment.

In the preliminary assessment of the stability of a slope due to a disturbing agent, there are two important issues to be considered - i.e. will the residual shear resistance $s_{R}$ stay greater than the in situ stress $\tau_{o}$ or not. The residual shear resistance.$s_{g}$ can be determined by relevant testing procedure or - which is probably most reliable - by back-analysis of similar landslides applying a progressive failure mode.

In the first case, i.e. if the residual stress $s_{R}$ remains $>\tau_{o}$, the slide movement will not be progressive in the sense used in this paper. The slope will essentially remain stable even when subjected to large deformations and the load $N_{q}$ will not be limited to any specific critical value in the disturbance phase.

In the second case, i.e. when the current value of $s_{R}$ may fall below $\tau_{o}$, the critical load $N_{c r}$ and the critical deformation $\delta_{\text {crit }}$ have to be determined and compared with currently applied loads and deformations.

A study of the critical load for different slope conditions is summarized in Figure 19.

The critical load in the example varies from $q_{\text {crit }}=7$ to $25 \mathrm{kN} / \mathrm{m}^{2}$ for different slope gradients and clay sensitivities $s_{R} / s_{\text {lab }}$. Note that the triggering load is relatively little affected by the degree of strain softening parameter - especially for steeper values of the slope gradient. The diagram also accentuates the acute hazard in respect of progressive failure related to local upslope fills and embankments.

Some issues typical of landslides in sensitive deformation-softening soils are: 
- Progressive failure entails that long slopes, which under drained conditions may have remained stable for thousands of years, can be destabilized by more or less un-drained deformation-softening response in the clay by seemingly insignificant local disturbing agents such as embankments, fills, pile-driving, vibration or blasting.

- Analysis of slope stability in long slopes based on short local slip surfaces (whether circular-shaped or plane) may yield highly erroneous results, simply because these modes of failure do not correspond to the actual failure mechanism, Bernander (2011), Jostad et al (2013). A serious consequence of this issue, in particular for road construction, is that earth fills designed to counteract the weight of road embankments often involve acute risk of a much more serious slide event than the one meant to be prevented by the supporting fill arrangement.

- Although quick clays involve particular risk in connection with landslide hazard, there are other factors that decisively contribute to progressive landslide formation and development. Such factors are e.g. the rate of applying the triggering additional load and the geometric features of the slope as exemplified in Figures 5 and 19. The importance of investigating the influence of creep on the stability of slopes is discussed by Pusch et al (2016).

- The finite difference analysis used for assessing progressive failure formation explains how it actually can come about that slides in soft sensitive clays tend to spread so far - i.e. often several hundred meters - over horizontal (or slightly inclining ground), deforming the soil mass in passive failure down to great depths as in the Surte and Tuve slides.

- The finite difference analysis also predicts that the incipient failure zone with its shear band tends to be established far beyond the foot of a slope well before the possible subsequent collapse in passive failure which, in fact, may or may not actually occur. 


\section{Conclusions}

The paper gives the following answerers to the questions posed in the Introduction:

(a) Local additional load effects may trigger extensive disastrous landslides in long natural slopes due to the sensitivity of the soil and to unfavorable slope features. In cases where the triggering load is surprisingly small, there may be parts of the slope area, where the resistant earth pressure just barely manages to carry the effects of gravitational forces.

(b) The shear deformations in the entire highly sheared zone must be considered in the analysis in order to be able to properly study the states of equilibrium and deformations in a slope. The size of the triggering load is directly dependent on the possible deformations in this zone (In a very narrow shear band, the triggering load would be insignificant). Landslides in western Sweden indicate that this highly sheared zone may well extend over a third of the depth of the potentially sliding soil volume.

(c) It is imperative to distinguish between different phases of a progressive landslide in order to understand the mechanisms of the slide and the different time scales in the different phases. Rates of loading as well as rates of change of shear stress are vital factors to be considered (d) One singular case of static loading or a singular failure criterion is not sufficient to assess the stability of a long slope of sensitive clay. At least two critical conditions have to be analyzed based on the in situ conditions:

(1) The triggering condition due to additional loading, (Phase 2);

(2) The down-slope passive failure condition defining the minimum extent and the scope of landslide disaster, (Phase 4).

Dynamic forces may likely increase the final length of a landslide;

(e) Zones of un-fractured clay (Stage I) and deformation softening clay in an established failure surface (Stage II) must be treated separately as they have vastly different properties; (f) Failure zones and slip surfaces tend to develop far beyond the foot of a slope, i.e. even prior to the incidence of possible passive failure. This is due to the fact that the pressure 
required to generate a progressive failure along a plane - more or less parallel to the ground surface - may actually be lower than the passive earth pressure resistance of the soil layers above this failure plane. .

It should now be the time for consulting geotechnical engineers to start applying Progressive failure analysis to long slopes with sensitive soils, especially if the triggering load is of local character. Yet, firstly, a basic understanding of the slide mechanisms is needed and the main purpose of this paper is to facilitate such an understanding. Secondly, a viable tool is needed for the analysis and as such a one, the finite difference method, is outlined here. Finite Element Methods are also apt for this purpose.

Finally it should be added that more research is needed, in particular regarding the residual shear resistance of sensitive clays and its manifest dependence of loading rate, excess pore water dissipation and the degree of over-consolidation.

\section{Acknowledgements}

The authors acknowledge the long-time support from SKANSKA, financial support from the Swedish Research Council Formas and from SBUF - the Development Fund of the Swedish Construction Industry as well as comments and criticism from many colleagues and friends including the many clarifying comments from the reviewers of this paper.

\section{References}

Bernander, S. 1978. Brittle Failures in Normally Consolidated Soils. Väg- \& Vattenbyggaren (Stockholm), No 8-9, pp 49-52. Most of Stig Bernander's Publications are accessible at $\underline{\text { http://pure.ltu.se/portal/sv/publications/search.html }}$ 
Bernander, S. 1985. On Limit Criteria for Plastic Failure in Strain-rate Softening Soils. Proc. $11^{\text {th }}$ ICSMFE, San Fransisco, Balkema, Vol. 1/A/2, pp $397-400$.

Bernander, S. 2000. Progressive Landslides in Long Natural Slopes. Formation, potential extension and configuration of finished slides in strain-softening soils. Licentiate Thesis 2000:16, Luleå University of Technology, ISSN: 1402 - 1757. 16+104+17 pp. Available at http://epubl.ltu.se/1402-1757/2000/16/index.html

Bernander, S. 2008. Down-hill Progressive Landslides in Soft Clays. Triggering Disturbance Agents. Slide Prevention over Horizontal or Gently Sloping Ground. Sensitivity related to Geometry. Research Report 2008:11, Luleå University of Technology, ISSN: 1402-1528, 16+101 pp. Available at http://epubl.ltu.se/1402-1528/2008/11/index.html

Bernander, S. 2011. Progressive Landslides in Long Natural slopes. Formation, Potential Extension and Configuration of Finished Slides in Strain-Softening Soils. Doctoral Thesis. Luleå University of Technology, Division of Soil Mechanics and Foundation Engineering in cooperation with the Division of Structural Engineering, 3rd revised version, April 2012, 252 pp, ISBN 978-91-7439-283-8. Available at http://pure.ltu.se/portal/files/36517492/Stig_Bernander.Rev._April_2012.pdf (Accessed 26 November 2015)

Bernander, S. and Olofsson, I. 1981. On Formation of Progressive Failures in Slopes. Proc. $10^{\text {th }}$ Int. Conf. Soil Mech. Found. Eng., ICSMFE, Stockholm 1981, Vol 3, 11/6, pp 357362.

Bernander, S. and Gustås, H. K. G. 1984. Consideration of in situ Stresses in Clay Slopes with Special Reference to Progressive Failure Analysis. Proc. IV $V^{\text {th }}$ Internat. Symposium on Landslides, Toronto, Downsview, Ont. Canadian Geotechnical Society, Vol 2, pp 235-240 
Bernander, S., Svensk, I., Holmberg, G., Bernander, J. and Isacsson, K. 1985. Shear strength and deformation properties of clays in direct shear tests at high strain rates. Proc. $11^{\text {th }}$ ICSMFE, San Fransisco, Balkema, Vol. 2/B/5, pp 987 - 990.

Bernander, S., Gustås, H. and Olofsson, J. 1989. Improved Model for Progressive Failure Analysis of Slope Stability. Proc. 12th ICSMFE, Rio de Janeiro, Balkema, Vol 21/3, pp 1539-1542.

Bishop, A.W. 1971. The influence of progressive failure on the choice of the method of stability analysis. Technical Notes, Géotechnique, Vol. 21 pp 168-172.

Bjerrum, L. 1967. Progressive failure in slopes of over-consolidated plastic clay and shales. 3rd Terzaghi Lecture presented in Miami Florida 1966. American Soc. of Civil Eng., $A S C E$, Journal of the Soil Mech. \& Foundations Division, Vol 93, , SM5, pp 3-49.

Bonadies, F., Nordal, S., Gylland, A.S, Grimstad, G., Jostad, H.P., Cuomo, S. and Cascini, L. 2014. Numerical methods for simulation of downward progressive landslides. In: "Numerical Methods in Geotechnical Engineering”, Ed. by Hicks, Brinkgrave \& Rohe, Taylor \& Francis Group, London, pp 579-584, ISBN 978-1-138-00146-6.

Caldenius and Lundström. 1956. ). The Landslide at Surte on the Göta River. Geological Survey of Sweden, SGU Report No 27, Publ. Stockholm.

Chen, S. Y., Zhang, X.S., Tang, W. S. 1997. A Numerical Method for Analyzing Progressive Process of Landslide in Soil Slope. Proc. of the $9^{\text {th }}$ International Conference on Computer Methods in Geomechanics, Wuhan, China, Balkema, Vol 13, pp 1627-1642

Christian, J.T. and Whitman, R.V. 1969. A one-dimensional model for progressive failure. Proc. $7^{\text {th }}$ Int. Conf. Soil Mech. Found. Eng., Mexico City, Sociedad Mexicana de Mecanica de Sulelos, Vol 2, pp 541-545.

Flodin, N. and Broms, B. 1981. History of Civil Engineering in Soft Clay. In "Soft Clay Engineering”, Edited by E. W. Brand and R. P. Brenner, Elsevier, Amsterdam, pp 25-156, ISBN 0-444-41784-2. 
Graham, J., Crooks, J.H.A, and Bell, A.L.1983. Time effects on the stress-strain behaviour of natural soft clays. Géotechnique, Vol. 33, No. 3, pp 327-340

Gylland, A. S. and Jostad H. P. 2010. Effect of updated geometry in analysis of progressive failure. Proc. $7^{\text {th }}$ European Conf. on Numerical Methods in Geotechnical Engineering, Trondheim, Norway, 2-4 June 2010, edited by T. Benz and S. Nordal, pp 497-502.

Gylland, A. S. 2012. Material and slope failure in sensitive clays. Trondheim: Norwegian University of Science and Technology, Department of Civil and Transport Engineering, Doctoral Thesis 2012:352, 238 pp.

Gylland, A. S., Jostad, H. P. and Nordal, S. 2014. Experimental study of strain-localization in sensitive clays, Acta Geotechnica, Vol. 9, No. 2, pp 227-240

Jostad, H. P., Fornes, P. and Thakur, V. 2013. Effect of strain-softening in design of fills on gently inclined areas with soft sensitive clays. Chapter 24 in Landslides in Sensitive Clays. From Geoscience to Risk Management. ed. by L'Heureux, J.-S., Locat, A., Leroueil, S., Demers, D. and Locat, J. Springer, pp 305-316, ISBN 978-94-007-7078-2.

L'Heureux, J.-S., Locat, A., Leroueil, S., Demers, D. and Locat, J., Editors. 2013. Landslides in Sensitive Clays. From Geoscience to Risk Management. Springer, 418 pp, ISBN 97894-007-7078-2.

Kjellman, W. 1955. Mechanics of Large Swedish Landslides. Géotechnique, Vol 5, No 1, pp 74-78.

Larsson, R. and Jansson M. 1982. The landslide at Tuve, November 30, 1977. Report No 18, Swedish Geotechnical Institute, Linköping, 154 pp.

Leroueil, S. 2001. Natural slopes and cuts - Movement and failure mechanisms. 39th Rankine Lecture. Géotechnique 51, No 3, pp 197-243.

Locat, A. 2007. Ėtude d'un étalement latéral dans les argiles de l'est du Canada et de la rupture progressive. Le cas du glissement de Saint-Barnabé-Nord. M.Sc. Thesis, 
Departement de Génie Civil, Faculté de Sciences et de Genie, Univ. Laval, Québec, 280

$p p$.

Locat, A., Leroueil, S., Bernander, S., Demers, D., Locat, J., and Ouehb, L. 2008. Study of a lateral spread failure in an eastern Canada clay deposit in relation with progressive failure: The Saint-Barnabé-Nord Slide. In Proc. of the 4th Canadian Conference on Geohazards. From Causes to Management, Edited by J. Locat, D. Perret, D. Turmel, D. Demers, and S. Leroueil. Presses de l’Université Laval, Québec, pp. 89-96.

Locat, A., Leroueil, S., Bernander, S., Demers, D., Jostad, H.P., and Ouehb, L. 2011. Progressive failures in eastern Canadian and Scandinavian sensitive clays. Canadian Geotechnical Journal, 48(11): 1696-1712, doi:10.1139/t11-059.

Locat, A. 2012. Rupture progressive et étalements dans les argiles sensibles (Progressive failure and spreads in sensitive clays). Ph.D. thesis, Département de génie civil et de génie des eaux, Université Laval, Québec, Que, 216 pp.

Locat, A., Jostad, H.P., and Leroueil, S. 2013. Numerical modeling of progressive failure and its implications for spreads in sensitive clays. Canadian Geotechnical Journal, 50(9), 961978, doi:10.1139/cgj-2012-0390.

Locat, A., Leroueil, S., Fortin, A., Demers, D., and Jostad, H.P. 2015. The 1994 landslide at Sainte-Monique, Quebec: geotechnical investigation and application of progressive failure analysis. Canadian Geotechnical Journal, 52(9), 490-504, doi:10.1139/cgj-2013-0344

Löfquist, B. 1973. Lerskred genom vattenupptryck (Slides in clays caused by hydraulic uplift. In Swedish).Väg- och vattenbyggaren, Stockholm, 19(2), pp 187-190.

Puzrin, A. M. 2016. Editorial: Modern trends in landslide mechanics. Géotechnique 66, No. 3, 173-174 [http://dx.doi.org/10.1680/jgeot.2016.66.3.173]

Pusch, R., Knutsson, S., Liu, X. and Yang, T. 2016. Creep can strengthen clay: A matter of long-term slope stability. Journal of Earth Sciences and Geotechnical Engineering, vol. 6, no.1, 2016, 1-18 ISSN: 1792-9040 (print), 1792-9660 (online) Scienpress Ltd, 2016 
Quinn, P. 2009. Large Landslides in Sensitive Clay in Eastern Canada and the Associated Hazard Risk to Linear Infrastructure. Ph D Thesis, Department of Geological Sciences and Geological Engineering, Queen's University, Kingston, Ontario, Canada. April 2009, 465 pp. Available at: http//qspace.library.queensu.ca/handle/1974/1781 (21 April 2011)

Rehnström, L. 2013. Analysis of Progressive Landslides. A review of the simplified calculation model. M Sc Thesis 2013:5, Div. of Geo Engineering, Chalmers University of Technology, Göteborg, $55 \mathrm{pp}$. Available at http://publications.lib.chalmers.se/records/fulltext/185611/185611.pdf

Saurer, E. 2009. Shear band propagation in soil and dynamics of tsunamigenic landslides. $P h$ D Thesis,ETH, Zürich, 188 pp. doi:10.3929/ethz-a-005951122. Available at: $\underline{\text { http//www.civil.iitb.ac.in/e.library.queensu }}$

Skempton A.W. 1964. 4th Rankine Lecture: Long Term Stability of Clay Slopes. Géotechnique, Vol. 14, No 2, pp 77-102.

Terzaghi, K. and Peck, R. B. 1948. Soil Mechanics in Engineering Practice. New York, John Wiley \& Sons, Inc.

Thakur, V. 2007. Strain Localization in Sensitive Soft Clays. Ph D Thesis, Geotechnical Division, Department of Civil and Transport Engineering, Norwegian Institute of Science and Technology, NTNU. Trondheim and Norwegian Centre of Excellence: International Centre for Geohazards, ISBN 9788247139097,188 pp.

Thakur, V. and Septanika, E.G. 2008. Extended finite element modeling (X-FEM) of progressive sliding in geomaterials, Nordic Geotech. Meeting, No. 15, Ed. by K. Flaate, T.-E. Frydenlund, J. Prestegarden and K. Senneset, pp 447- 469.

Troncone, A. 2005. Numerical analysis of a landslide in soils with strain-softening behavior. Géotechnique, Vol 55. No. 8, pp 585-596.

Zabala, F. and Alonso, E.E. 2011. Progressive failure of Aznalcollar dam using the material point method, Geotechnique, Vol 61, No. 9, pp 795-808. 
Zhang, W., Wang, D., Randolph, M.F. and Puzrin, A.M. 2015. Catastrophic failure in planar landslides with a fully softened weak zone. Géotechnique 65, No 9, 755-769.

doi.org/10.1680/geot14.P.218. 


\section{Appendix. Basic procedure using the Finite Difference Method}

Figure A1 illustrates the principles and the integration procedure for the proposed Finite Difference Method of analysis. The aim is to determine the maximum load effect, $q_{c r}$, that can be applied in a certain up-slope location.

The integral computation begins at a point, $x=0$, further down the slope, where the conditions of stress and deformation are unaffected by the applied additional load, q. Hence, the parameters for earth pressure $E_{0, x=0}$, in situ shear stress $\tau_{0, x=0}$, load effect $N_{x=0}$ and down-slope displacement $\delta_{x=0}$ constitute the down-slope boundary condition for the subsequent integral analysis. Correspondingly, the force $N_{L}$ at $x=L$ is the up-slope boundary condition that, when satisfied, determines the associated values of $\tau_{x=L}$ and $\delta_{x=L}$. The force $N_{L}=f(q)$ can often here approximately be taken as $N_{L} \approx$ $q H_{L}$ where $q\left(\mathrm{kN} / \mathrm{m}^{2}\right)$ is the applied load and $H_{L}(\mathrm{~m})$ is the height of the slope. In Figure 19 , the boundary condition at $x=0$ is defined as: $E_{x}=E_{0, x=0}, \tau_{x}=\tau_{0, x=0}, N_{x}=0$, and $\delta_{x}=0$. The procedure can be subdivided into the following steps:

Step 1. The integration process starts at a point $(x=0)$ further down the slope, where the influence of the additional load $N_{q}$ is negligible, by choosing an initial shear stress increment at the potential failure plane $\Delta \boldsymbol{\tau}_{1}$ at a distance $x=\Delta \boldsymbol{x}_{1}$. The corresponding increase of the normal force $N_{1}$ and the associated downhill axial displacement $\delta_{1}$ may then directly be determined, rendering the following values at $x_{1}$ namely $\tau_{x,}(z=0)=\tau_{0}+\Delta \tau_{1}=\tau_{1}, N_{x}=N_{1}$ and $\delta_{x}\left(N_{1}\right)=\delta_{1}$

Step 2. As indicated in Figure 19, the calculation proceeds by advancing in steps of suitably chosen values of $\Delta \tau$ and $\Delta x$. As the values of $\delta_{N}$ and $\delta_{\tau}$ can then be expressed in terms of the assumed values of the increments $\Delta \tau$ and $\Delta x$, the correlating values of $\Delta x$ and $\Delta \tau$ in each step cycle have to be found by iteration so that the compatibility equation is satisfied, i.e.: 


$$
\delta_{N, x}=\sum_{0}^{x}\left(\Delta \delta_{N}\right)=\delta_{\tau, x}
$$

A trial value for $\Delta \tau_{2}$ and a corresponding value of $x_{2}=x_{1+} \Delta x_{2}$ are assumed. The value of $N_{2}$ is then $N_{1}$ $+\Delta \tau_{2} \cdot \Delta x_{2}$ and the related value of additional displacement $\Delta \delta_{x}\left(N_{1-2}\right)=$

$=\left(N_{1}+N_{2}\right) \cdot \Delta x_{2} /\left(2 H E_{\text {clay }}\right)$ and $\delta_{x}\left(N_{2}\right)=\delta_{2}$ can be calculated. Here $E$ is the compression modulus of elasticity of the clay. Yet, the downhill displacement $\delta_{x}\left(N_{2}\right)$ has to be compatible with the shear deformation $\delta_{x}\left(\tau_{2)}\right.$ at $x_{2}$. This value is determined by integration over the zone subject to intense shear - i.e. from $z_{x, 2}=0$ to $z_{x, 2}=\alpha \cdot H_{x}$, where $\alpha$ is a measure of the thickness of this zone, $(\alpha$ usually taken to be about $1 / 3$ in accordance with data from studies of landslides occurred of the current kind). The shear zone is subdivided into differentials of $\Delta z$.

However, the double integration analysis being an iterative procedure, a compatibility criterion demanding that $\delta_{x}\left(N_{2}\right)=\delta_{x}\left(\tau_{2}\right)$ has to be satisfied. This condition is not likely to be fulfilled in the first attempt, i.e. $\delta_{x}\left(\tau_{2}\right) \neq \delta_{x}\left(N_{2}\right)$

By selecting new values of $\Delta \tau$, this equation can readily be adjusted so that the compatibility criterion is satisfied, i.e.

\section{$\delta_{x}(\tau)=\delta_{x}(N)$}

Step 3. At this point, a new stress increment $\Delta \tau_{3}$ at $x_{3}=x_{2}+\Delta x_{3}$ is tried, again determining the corresponding increase of the normal force $N_{3}$ and the downhill displacement $\delta_{3}(N)$

In each step of the continued integration process, the downhill displacement is determined by repeating the iterative procedure in Step 2, whereby also the parameters $\boldsymbol{\tau}_{x, z=0}, \boldsymbol{N}_{x}$ and $\boldsymbol{\delta}_{x}$ are calculated for each value of $\mathrm{x}$. The boundary condition to be satisfied in the current case is that $\boldsymbol{N}_{\boldsymbol{x}}$ for $x=L$ is equal to the additional load $N_{\mathrm{q}} \approx q \cdot H_{L}$. In slopes with complex geometry, this boundary condition is not initially likely to be fulfilled, in which case an alternative position for the starting point $(x=0)$ has to be chosen. 
This analysis may appear to be extremely laborious. Yet, using computer software, a trial and error integration of this kind is a matter of seconds once all relevant slope data have been introduced.

Applications using spreadsheets are given in Appendices in Bernander (2008) and (2011). A simplified version is presented in Rehnström (2013). 


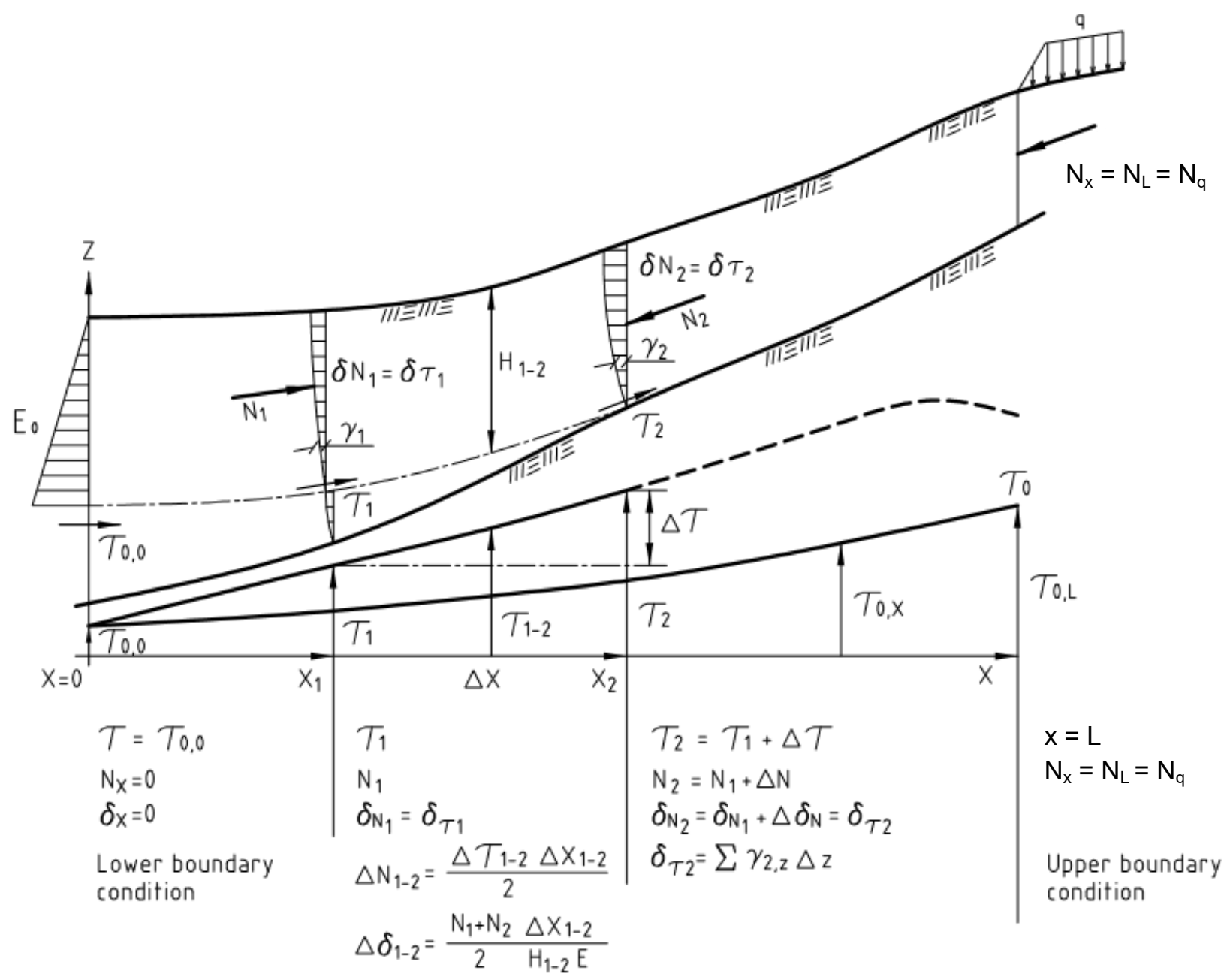

Figure A1. Section illustrating the calculation procedure. 


\section{List of symbols}

$\alpha$

$\beta$

$\delta$

$\gamma$

$\sigma$

$\tau$

$\rho g$

E

$F$

G

H

K

$L$

$N$

$q$

$x$ is the relative thickness of the zone where most of the shear deformations take place

is the inclination of a studied slope or of a part of the same

is the deformation caused by shear forces, slip; or a differential part of a

function

is the shear deformation

is the normal stress

is the shear stress

is the density where $g$ is the gravitational acceleration

is the total downslope load in the earth $\left(=E_{\mathrm{o}}+N\right)$; or the modulus of elasticity

is the safety factor at failure conditions

is the shear modulus

is the depth of a failure plane under the ground surface

is the relationship between horizontal and vertical stresses (In general the total stress)

is the length of the failure zone

is the downhill compression force acting above the assumed potential (or the established) failure surface due to the triggering load

$S$

is the peak shear stress $\left(=\tau_{\max }\right)$

is the locally applied triggering surface load on the slope (see Figure 2)

is a coordinate along the potential or the established failure plane, where $x=0$

defines a point where the influence of $N_{\mathrm{q}}$ is negligible

is a vertical coordinate from the failure plane 


\section{Indices}

$0 \quad$ denotes in situ parameters

a, b, c, d, e, different moments during a slope failure

crit critical value

el elastic

f failure; or value at maximum

h horizontal

instab value when a parameter changes from a stable to an unstable condition

1, lab laboratory

$\max \quad \operatorname{maximum}$

$\mathrm{p} \quad$ length of passive Rankine failure zone at the end of the slope

P passive earth pressure

R Residual; or a Rankine earth pressure condition

q $\quad$ caused by a load $\mathrm{q}$

v vertical 
Table 1. Input parameters and results for the Surte slide

\begin{tabular}{llll}
\hline Elastic parameters & $\begin{array}{l}\text { Maximum } \\
\text { parameters }\end{array}$ & Loads and & Lengths and \\
$\gamma_{\mathrm{el}}$ & $\gamma_{\mathrm{f}}$ & Earth pressures & Deformations \\
$\tau_{\mathrm{el}}$ & $s$ & $\mathrm{~N}$ & $\mathrm{~L}$ \\
$\mathrm{G}=\tau_{\mathrm{el}} / \gamma_{\mathrm{el}}$ & $s_{\mathrm{R}} / s$ & $K_{\mathrm{o}}=\sigma_{\mathrm{h}} / \sigma_{\mathrm{v}}$ & $\delta$ \\
$E=2(1+v) G \approx 3 G$ & &
\end{tabular}

Phase 1 - In situ condition

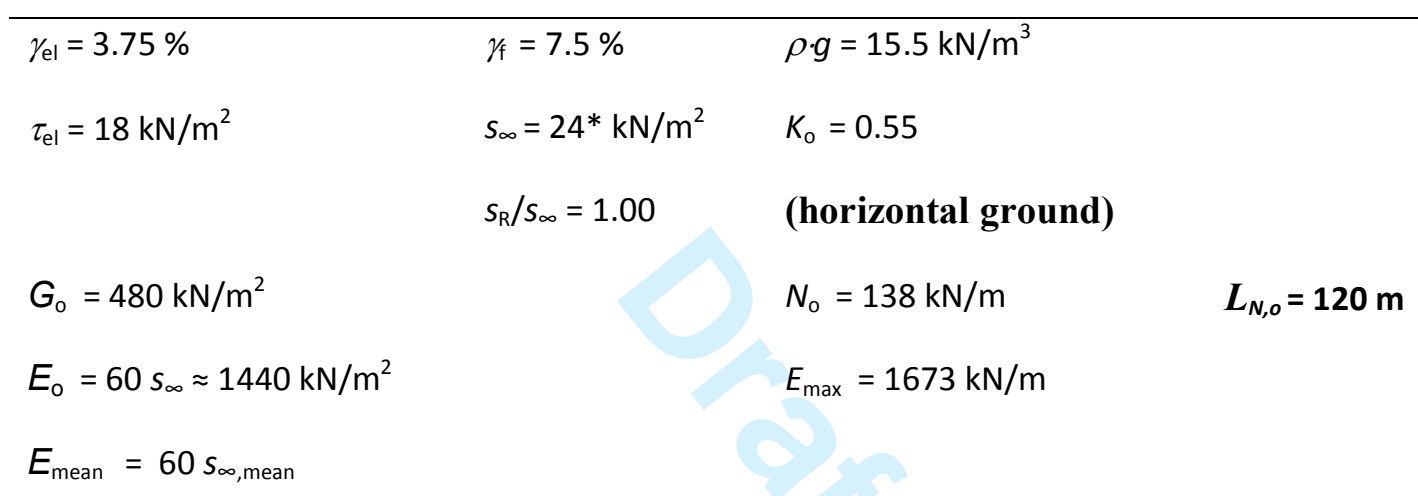

Phase 2 - Disturbance condition

\begin{tabular}{|c|c|c|c|}
\hline$\gamma_{\mathrm{el}}=2 \%$ & $\gamma_{f}=4.00 \%$ & & \\
\hline$\tau_{\mathrm{el}}=20 \mathrm{kN} / \mathrm{m}^{2}$ & $\begin{array}{l}s=30 * * \mathrm{kN} / \mathrm{m}^{2} \\
s_{\mathrm{R}} / s=0.60 * *\end{array}$ & $\begin{array}{l}K_{\mathrm{o}}^{\max }=0.594 \\
\text { (computed) }\end{array}$ & \\
\hline$G_{o}=1000 \mathrm{kN} / \mathrm{m}^{2}$ & Force induced: & $N_{\mathrm{cr}}=192 \mathrm{kN} / \mathrm{m}$ & $L_{N}=0 \mathrm{~m}$ \\
\hline$E_{o}=100 \mathrm{~s} \approx 3000 \mathrm{kN} / \mathrm{m}^{2}$ & & $E_{\max }=1665 \mathrm{kN} / \mathrm{m}$ & $L_{c r}=114 \mathrm{~m}$ \\
\hline \multirow[t]{4}{*}{$E_{\text {mean }}=100 \cdot \mathrm{s}_{\text {mean }}$} & & & $\delta_{\mathrm{cr}}=0.15 \mathrm{~m}$ \\
\hline & Deformation & $N_{\mathrm{cr}}=0 \mathrm{kN} / \mathrm{m}$ & $L_{\mathrm{N}}=50 \mathrm{~m}$ \\
\hline & induced: & $E_{\max }=1770 \mathrm{kN} / \mathrm{m}$ & $L_{\text {instab }}=162 \mathrm{~m}$ \\
\hline & & & $\delta_{\text {instab }}=0.29 \mathrm{~m}$ \\
\hline
\end{tabular}




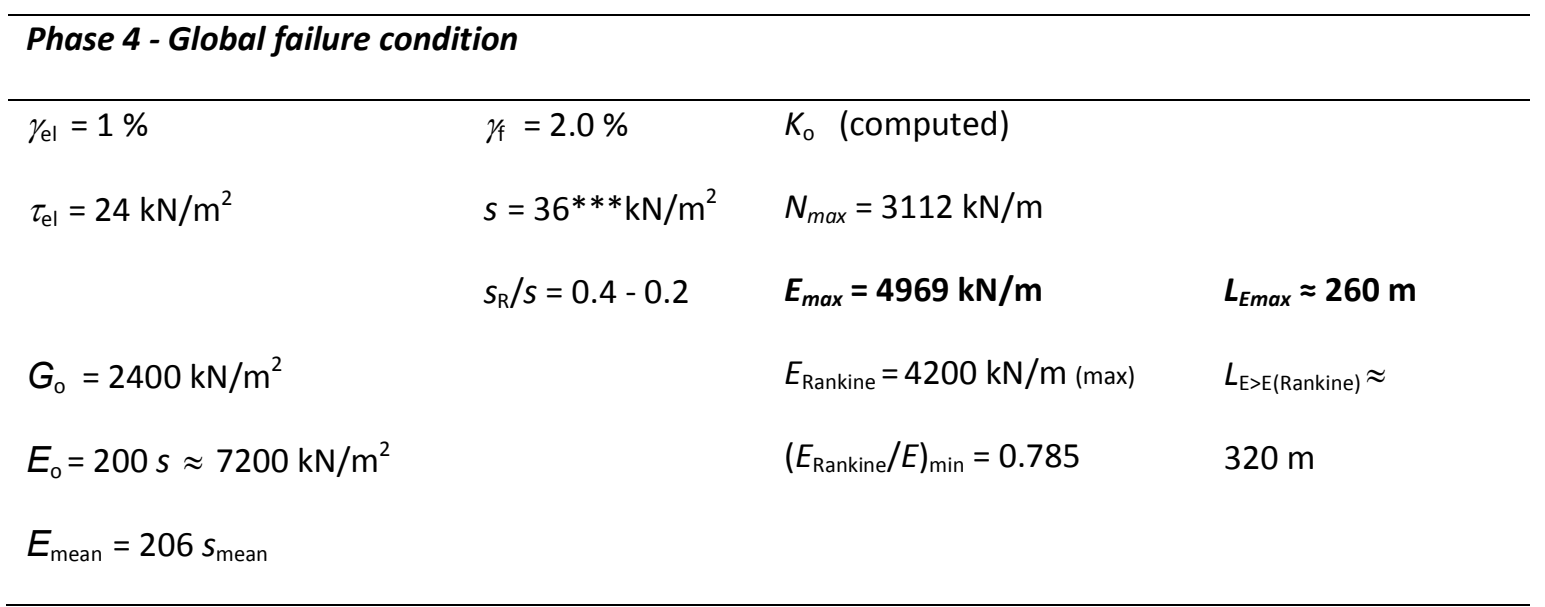

* In the current state, $s_{\infty}$ signifies the long time shear resistance - drained conditions

** Mean values applying to the initiation zone

*** Mean value applying to the down-slope failure zone

$N_{o}$ is unbalanced forces present already in the in situ conditions

$L_{N, o}$ is the distance to $N_{o}$ from the point where the influence of it is negligible

$L_{N}$ is the distance to $N_{\max }$ from the point of application of additional load

$L_{i n s t a b}$ is the length over which the force $N x$ is positive

$L_{E \max }$ is the distance to $E_{\max }$ from the point of application of additional load

$L_{E>E(\text { Rankine })}$ is the length over which passive Rankine resistance is exceeded 
Table 2. Input parameters and results for the Tuve slide

\begin{tabular}{llll}
\hline Elastic parameters & $\begin{array}{l}\text { Maximum } \\
\text { parameters }\end{array}$ & Loads and & Lengths and \\
$\gamma_{\mathrm{el}}$ & $\gamma_{\mathrm{f}}$ & $N$ & Deformations \\
$\tau_{\mathrm{el}}$ & $s$ & $E$ & $L$ \\
$G=\tau_{\mathrm{el}} / \gamma_{\mathrm{el}}$ & $s_{\mathrm{R}} / s$ & $K_{\mathrm{o}}=\sigma_{h} / \sigma_{v}$ & $\delta$ \\
$E=2(1+v) G \approx 3 G$ & &
\end{tabular}

Phase 1 - In situ condition

\begin{tabular}{|c|c|c|c|}
\hline$\gamma_{\mathrm{el}}=2.5 \%$ & $\gamma_{\mathrm{f}}=7.5 \%$ & $\rho \cdot g=16.5 \mathrm{kN} / \mathrm{m}^{3}$ & \\
\hline$\tau_{\mathrm{el}}=12 \mathrm{kN} / \mathrm{m}^{2}$ & $\begin{array}{l}s_{\infty}^{*}=24 \rightarrow 30 \\
k N / m^{2}\end{array}$ & $K_{\mathrm{o}}=0.64$ & \\
\hline$G_{0}=480 \mathrm{kN} / \mathrm{m}^{2}$ & $s_{R} / s_{\infty}=1.00$ & $N_{\circ}=671 \mathrm{kN} / \mathrm{m}$ & $L_{N, o}=240 \mathrm{~m}$ \\
\hline$E_{o}=60 s_{\infty} \approx 1440 \mathrm{kN} / \mathrm{m}^{2}$ & & $E_{\mathrm{o}}=4169 \mathrm{kN} / \mathrm{m}$ & \\
\hline$E_{\text {mean }}=60 s_{\infty \text {,mean }}$ & & & \\
\hline
\end{tabular}

Phase 2 - Disturbance condition (force induced)

\begin{tabular}{|c|c|c|c|}
\hline$\gamma_{\mathrm{el}}=2 \%$ & $\gamma_{\mathrm{f}}=4.67 \%$ & & \\
\hline$\tau_{\mathrm{el}}=16.2 \mathrm{kN} / \mathrm{m}^{2}$ & $\begin{array}{l}s=27 * \rightarrow 33 * * \\
\mathrm{kN} / \mathrm{m}^{2} \\
s_{\mathrm{R}} / s=0.60\end{array}$ & $\begin{array}{l}K_{\mathrm{o}} * * * \\
N_{\mathrm{cr}}=75.8 \mathrm{kN} / \mathrm{m}\end{array}$ & $L_{\mathrm{cr}}=91.2 \mathrm{~m}$ \\
\hline$G_{0}=810 \mathrm{kN} / \mathrm{m}^{2}$ & & $E_{\max }=2572 \mathrm{kN} / \mathrm{m}$ & $\delta_{\mathrm{cr}}=0.055 \mathrm{~m}$ \\
\hline \multicolumn{4}{|c|}{$E_{0}=90 \cdot \mathrm{s} \approx 2430 \mathrm{kN} / \mathrm{m}^{2}$} \\
\hline$E_{\text {mean }}=90 \cdot \mathrm{s}_{\text {mean }}$ & & & \\
\hline
\end{tabular}

Phase 4 - Global failure condition 


\begin{tabular}{|c|c|c|c|}
\hline$\gamma_{\mathrm{el}}=1 \%$ & $\gamma_{\mathrm{f}}=2.0 \%$ & $K_{\mathrm{o}} * * *$ & \\
\hline \multirow[t]{2}{*}{$\tau_{\mathrm{el}}=20 \mathrm{kN} / \mathrm{m}^{2}$} & $s=30^{*} \rightarrow 40^{* *}$ & $N_{\max }=9128 \mathrm{kN} / \mathrm{m}$ & \\
\hline & $\mathrm{kN} / \mathrm{m}^{2}$ & $E_{\max }=15035 \mathrm{kN} / \mathrm{m}$ & $L_{E \max } \approx 456 \mathrm{~m}$ \\
\hline$G_{0}=2000 \mathrm{kN} / \mathrm{m}^{2}$ & $s_{R} / s=0.3-0.1$ & $\begin{array}{l}E_{\text {Rankine }}=12852 \mathrm{kN} / \mathrm{m} \\
\text { (varies) }\end{array}$ & $\begin{array}{l}L_{\mathrm{E}>\mathrm{E}(\text { Rankine })} \approx 450 \\
\mathrm{~m}\end{array}$ \\
\hline$E_{\mathrm{o}} \approx 6000 \mathrm{kN} / \mathrm{m}^{2}$ & & & \\
\hline$E_{\text {mean }}=200 s_{u, \text { mean }}$ & & $\left(E_{\text {Rankine }} / E\right)_{\min }=0.84$ & \\
\hline
\end{tabular}

* Mean values applying to the initiation zone.

** Mean values applying to the down-slope failure zone.

*** As computed in the in-situ condition

$N_{o}$ is unbalanced forces present already in the in situ conditions

$L_{N, o}$ is the distance to $N_{o}$ from the point where the influence of it is negligible

$L_{N}$ is the distance to $N_{\max }$ from the point of application of additional load

$L_{E \max }$ is the distance to $E_{\max }$ from the point of application of additional load

$L_{E>E(\text { Rankine) }}$ is the length over which passive Rankine resistance is exceeded 


\section{Figure captions}

Appendix Figure A1. Section illustrating the calculation procedure.

Figure 1 Stress-strain $(\tau / \gamma)$ and stress-deformation $(\tau / \delta)$ relationships in the studied example. Stage I is the condition before $\tau$ reaches $\tau_{\max }=s$ and Stage II represents the subsequent deformation softening development. The relationship can be varied within wide limits over the height and length of a slope.

Figure 2. Slope geometry (top), shear stresses $\tau$ (middle) and sustained earth compression force $N$ (bottom) for five consecutive moments a $\rightarrow$ e illustrating the effects of increasing influential lengths $L$ for changing upslope load, $N_{q}$. The critical conditions $c$ and $e$ are marked with bold lines.

Figure 3. The displacement $\delta$ at the point of loading as a function of the load above the shear surface $E=E_{\mathrm{o}}+N$ for the slope in Figure 2. $E_{0}$ represents the in situ earth pressure. Three vital phases in the development of a landslide are indicated together with loads and displacements for the five moments a $\rightarrow$ e.

Figure 4. Critical triggering situation at the end of Phase 2 (Moment c in Figures 2 and 3 ) with $N_{q}=$ $N_{\text {crit }}$. The situation marks the transition between Phase 2 and the virtually dynamic Phase 3 . The inelastic slip $\delta_{\mathrm{s}}$ develops when the shear stress $\tau$ exceeds its peak value $s$ thus entering the strain deformation softening Stage II. 
Figure 5. Phase 4 Shear stress development $\tau$ in a gentle slope ahead of an applied load $N=0,95 E_{R}$ (passive Rankine earth pressure). Prior to passive failure a fully developed failure zone $L_{p}$ extends far beyond the foot of the slope.. The maximum shear stress $1,2 \mathrm{~s}$ is in the current state assumed to be $20 \%$ higher than $s_{\text {lab }}$ obtained in laboratory tests. The deformations $\delta$ for various degrees of sensitivity $s_{R} / s$ are shown in the lower figure. Bernander (2008).

Figure 6. Phases 4 and 5. Case 1 with a residual stress $s_{\mathrm{R} 1}=15 \mathrm{kPa}$ represents a condition, where passive Rankine resistance just balances the forces acting downhill in Phase $4, E_{\mathrm{P}}=E_{\mathrm{o}}+N_{1}$, thus constituting the decisive boundary criterion for a veritable landslide incidence. Case 2 with lower residual stress $s_{\mathrm{R} 2}=10 \mathrm{kPa}$ illustrates a Phase 5 condition,, in which the passive earth pressure resistance $E_{\mathrm{p}}$ is exceeded. The coordinates $x_{1}$ and $x_{2}$ are the locations of the peak earth pressures $\left(E_{o^{+}}+\right.$ $N,)_{\max }$

Figure 7. Final configuration of a downhill slide. Note that there may be a zone with undisturbed soil between the active zone (where the load was applied) and the disintegrated zone in the passive Rankine zone, where the dynamic forces of the sliding masses are moderate (ranging between active and passive earth pressure).

Figure 8. The basic principle for the finite difference calculation is that the deviatory deformation $\Delta \delta_{\tau}$ due to an increase of the shear stress $\Delta \tau$ is set equal to the deformation $\Delta \delta_{N}$ related to the corresponding increase of the normal force $\Delta N$. 
Figure 9. Aerial view of the Surte landslide in the valley of the Göta River some $10 \mathrm{~km}$ North of the city of Gothenburg, Sweden. From North looking South.

Figure 10. Aerial photograph taken 13 days after the Surte slide. From Caldenius and Lundström (1956).

Figure 11. Plan of the Surte slide area showing elevation contours and a longitudinal section A-A of the slide. The point marked $(\mathrm{P})$ on the plan is the location in the steepest portion of the slope, where piling operations were going on at the time of the slide occurrence. Section B-B marks the section being analysed in Figure 13.

Figure 12 Stress-deformation relationships for different phases of a slide: In situ (Phase 1), Disturbance (Phase 2) and Global failure (Phase 4 and 5). See also Table 1.

Figure 13 Static earth pressure distribution in the Surte slide in Phase 4 subsequent to the progressive failure phase (Phase 3) but prior to the slide proper resulting in disintegration and heave in a state of passive failure (Phase 5). The figure indicates that the static forces developed in the progressive phase of the ground movement suffice to explain the passive spread of the passive zone over almost horizontal ground.

Figure 14. Aerial photograph of the Tuve slide with East in the top.. Copyright Gothenburg Museum of Natural History. 
Figure 15. The landslide at Tuve, 1977. Topography of the valley before the slide and boundaries of the slide area. Results of the analysis of the initial downhill slide, i.e. below boundary B-B, are shown in Figure 16. Bernander (2011).

Figure 16. Tuve landslide. Static earth pressure distribution (top), shear stresses (middle) and elevation (bottom), subsequent to the progressive failure phase but prior to the slide proper resulting in disintegration and heave in passive failure, (Phase 5). A major part of the spread of the passive zone over almost horizontal ground can be ascribed to the forces developed at the end of the dynamic progressive Phase 3 of the ground movement, Bernander (2000).

Figure 17. Dynamic analysis illustrating elevations and shear stresses at different times from the initiation of a slide in the upper left part of the figure: (a) Phase 3, (b) Phase 4 and (c) Phase 5. In the elevations, increasing earth pressure intensities are illustrated with shades of yellow $\rightarrow$ green $\rightarrow$ dark green $\rightarrow$ black, where black indicates that passive Rankine pressure is exceeded. In the shear stress diagrams the red color indicates from right to left: increasing stresses, peak stress $s$, and softening reaching the residual stress $s_{R}$; the orange or yellow color indicates the difference between shear stresses due to forces acting downhill and the resistance $s_{R}$. Bernander and Gustås (1984), Bernander $(2000,2011)$

Figure 18. Plan and section through the slide area at Rävekärr. Observe the gentle slope gradient. Slip surfaces were documented at depths of $5-7 \mathrm{~m}$ in the upper part of the slide and angular deformations were recorded at $13 \mathrm{~m}$ and $33 \mathrm{~m}$ depth in the lower parts of the valley. Pile driving took place at the point marked $x$. Redrawn from Lövquist (1973). 
Figure 19. Critical triggering load $q_{c r i t}$ as function of slope inclination and residual shear resistance $s_{R} / s_{l a b}$, where $s_{R}$ is the ultimate residual stress and $s_{l a b}$ is the maximum stress obtained in laboratory tests. Bernander (2008). 


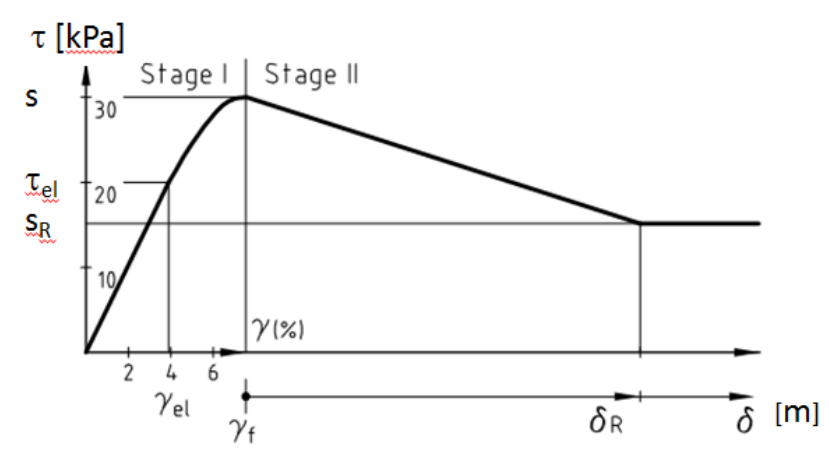

Figure 1 Stress-strain $(\tau / \gamma)$ and stress-deformation $(\tau / \delta)$ relationships in the studied example.

Stage I is the condition before $\tau$ reaches $\tau_{\max }=s$ and Stage II is the subsequent deformation softening part. The relationship can be varied within wide limits over the height and length of a slope. 


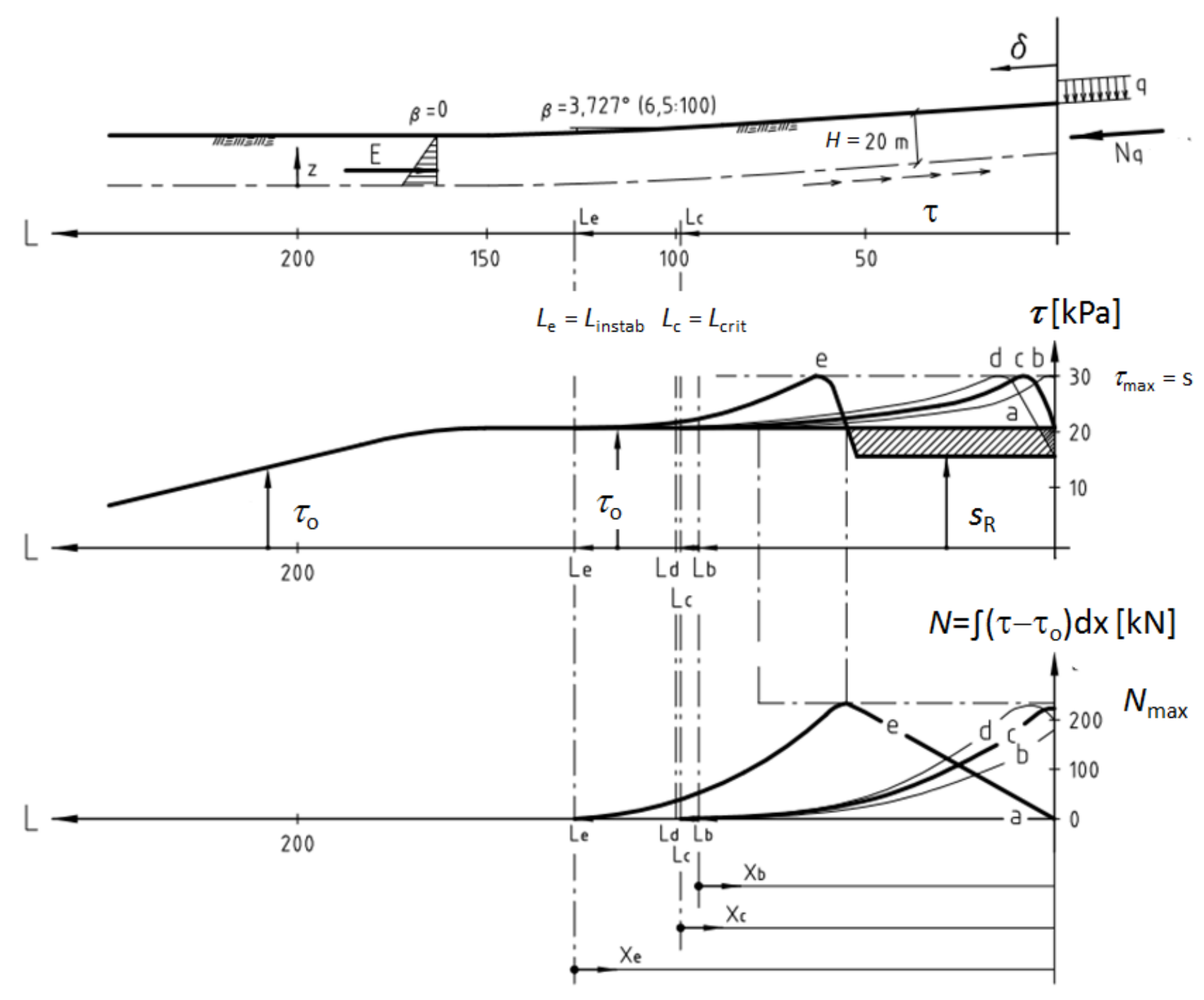

Figure 2. Slope geometry (top), shear stresses $\tau$ (middle) and sustained earth compression force $N$ (bottom)

for five consecutive moments a $\rightarrow \mathrm{e}$ illustrating the effects of increasing influential lengths $L$ for changing upslope load, $N_{q}$. 


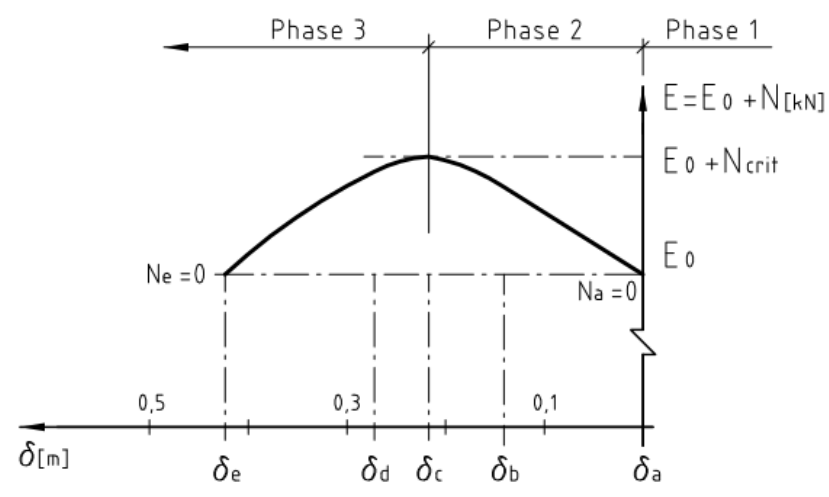

Figure 3. The displacement $\delta$ at the point of loading as a function of the load above the shear surface $E=E_{\mathrm{o}}+N$ for the slope in Figure 2. $E_{0}$ represents the in situ earth pressure. Three vital phases in the development of a landslide are indicated together with loads and displacements for the five moments $\mathrm{a} \rightarrow \mathrm{e}$. 


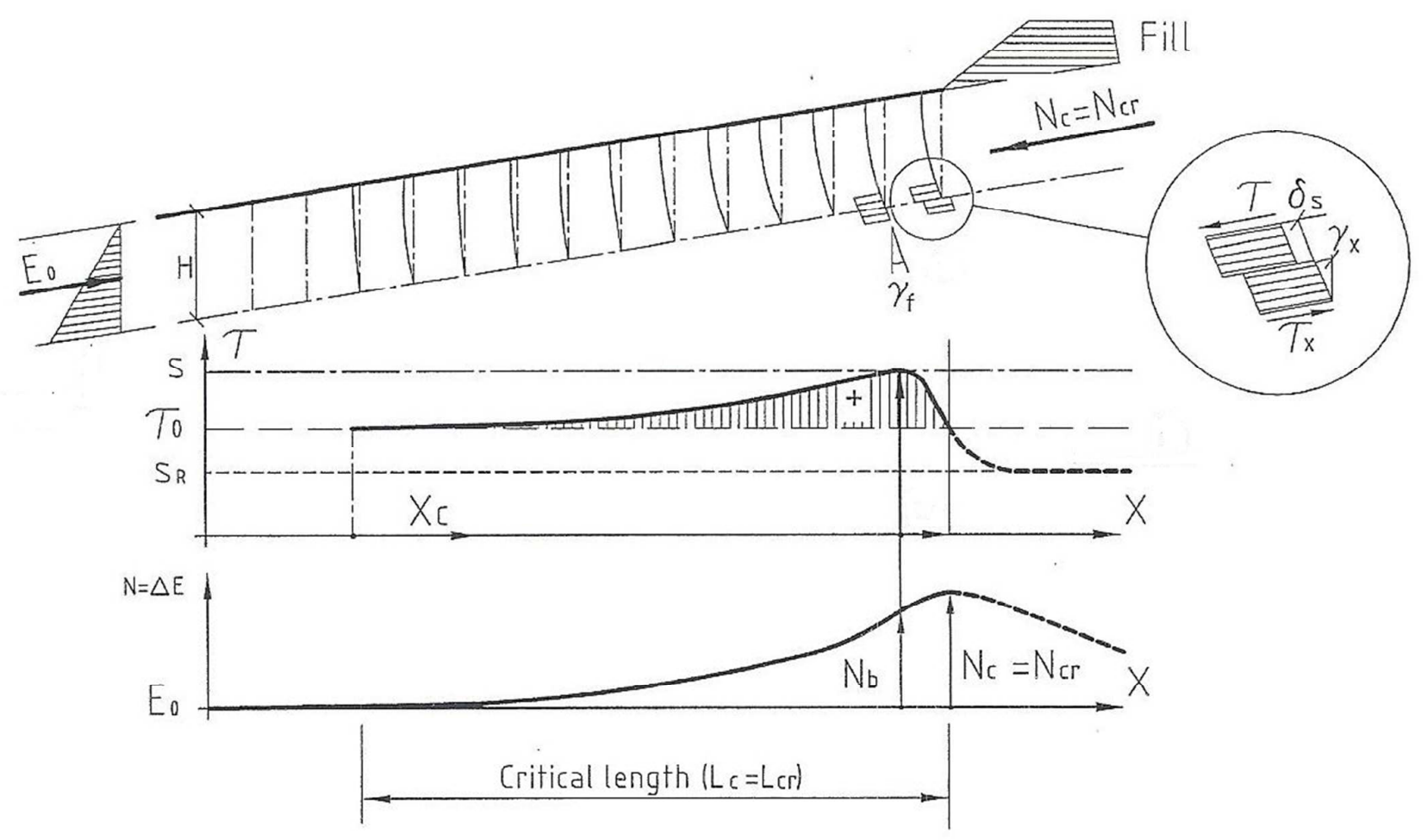

Figure 4. Critical triggering situation at the end of Phase 2 (Moment c in Figures 2 and 3) with $N_{q}=N_{c r i t}$. The situation marks the transition between Phase 2 and the virtually dynamic Phase 3. The inelastic slip $\delta_{\mathrm{s}}$ develops when the shear stress $\tau$ exceeds its maximum value $s$ thus entering the strain deformation softening Stage II. 

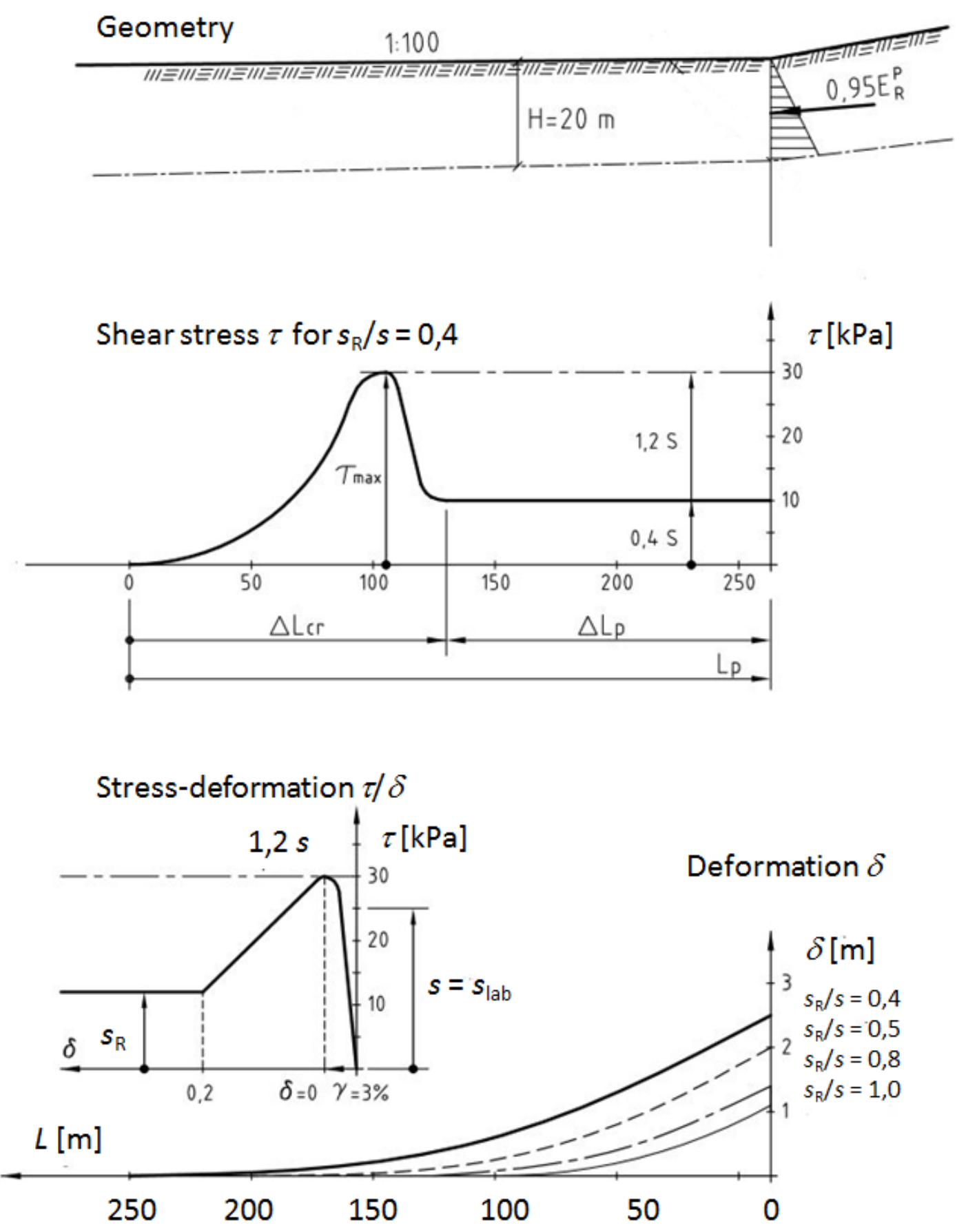

Figure 5. Phase 4 Shear stress development $\tau$ in a gentle slope ahead of an applied load $N=$ $0,95 E_{\mathrm{R}}$ (passive Rankine earth pressure). Prior to passive failure a fully developed failure zone $L_{P}$ extends far beyond the foot of the slope.. The maximum shear stress $1,2 \mathrm{~s}$ is in the current state assumed to be $20 \%$ higher than $s_{l a b}$ obtained in laboratory tests. The deformations $\delta$ for various degrees of sensitivity $s_{R} / s$ are shown in the lower figure. Bernander (2008). 


\section{Slope data}
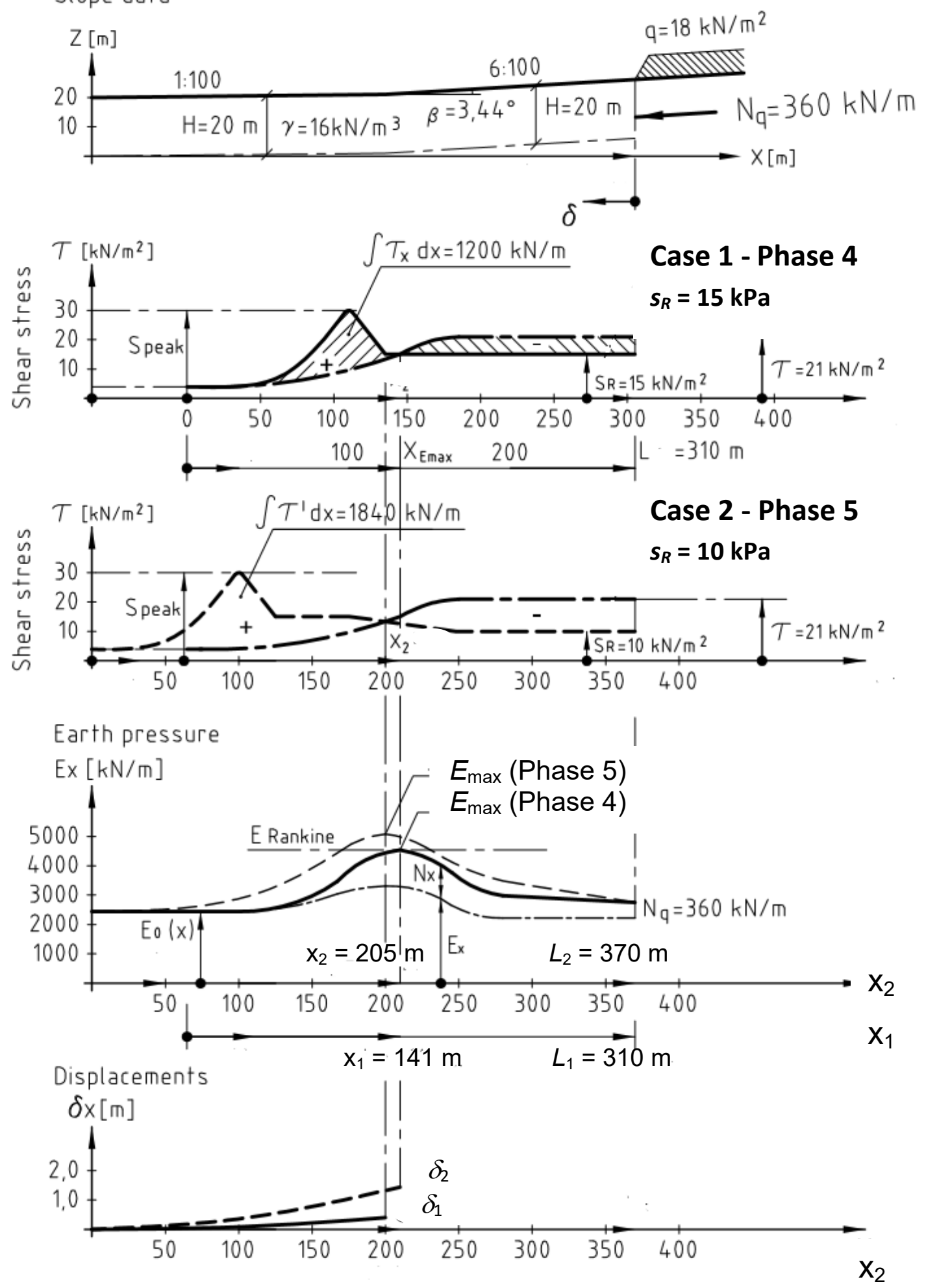
Figure 6. Phases 4 and 5. Case 1 with a residual stress $s_{\mathrm{R} 1}=15 \mathrm{kPa}$ represents a condition, where passive Rankine resistance just balances the forces acting downhill in Phase $4, E_{\mathrm{P}}=E_{\mathrm{o}}$ $+N_{1}$, thus constituting the decisive boundary criterion for landslide incidence. Case 2 shows a Phase 5 condition, with lower residual stress $s_{\mathrm{R} 2}=10 \mathrm{kPa}$, in which the passive earth pressure resistance $E_{\mathrm{P}}$ is exceeded. The coordinates $x_{1}$ and $x_{2}$ are the locations of the peak earth pressures $\left(E_{o}+N\right)_{\max }$. 


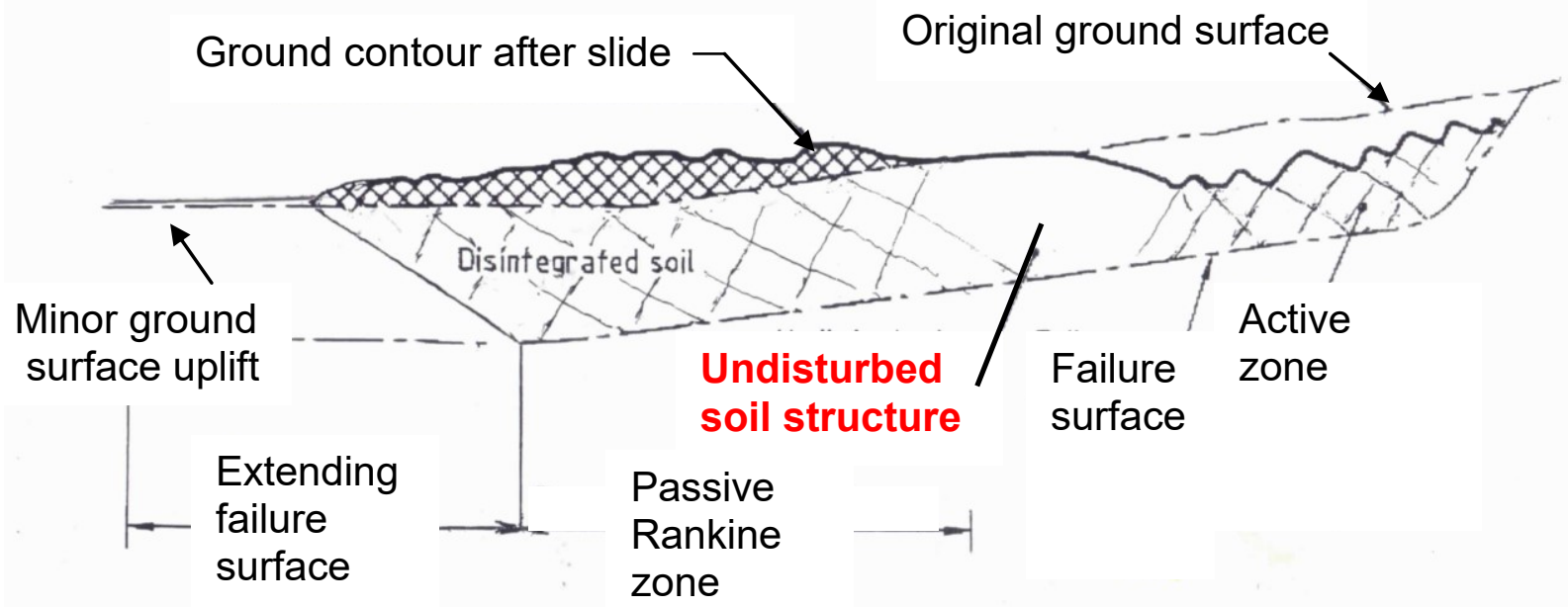

Figure 7. Final configuration of a downhill slide. Note that there may be a zone with undisturbed soil between the active zone (where the load was applied) and the disintegrated zone in the passive Rankine zone, where the dynamic forces of the sliding masses are moderate (ranging between active and passive earth pressure). 


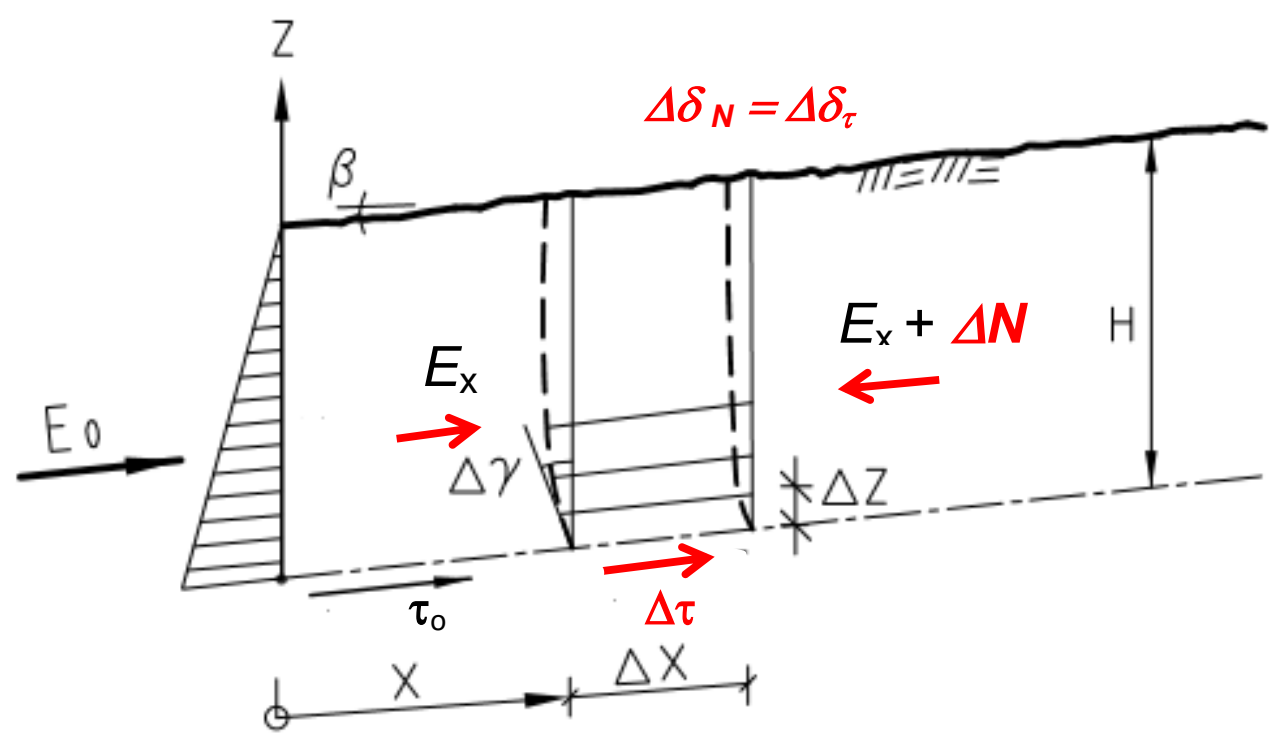

Figure 8. The basic principle for the finite difference calculation is that the deviatory deformation $\Delta \delta_{\tau}$ due to an increase of the shear stress $\Delta \tau$ is set equal to the deformation $\Delta \delta_{N}$ related to the corresponding increase of the normal force $\Delta N$. 


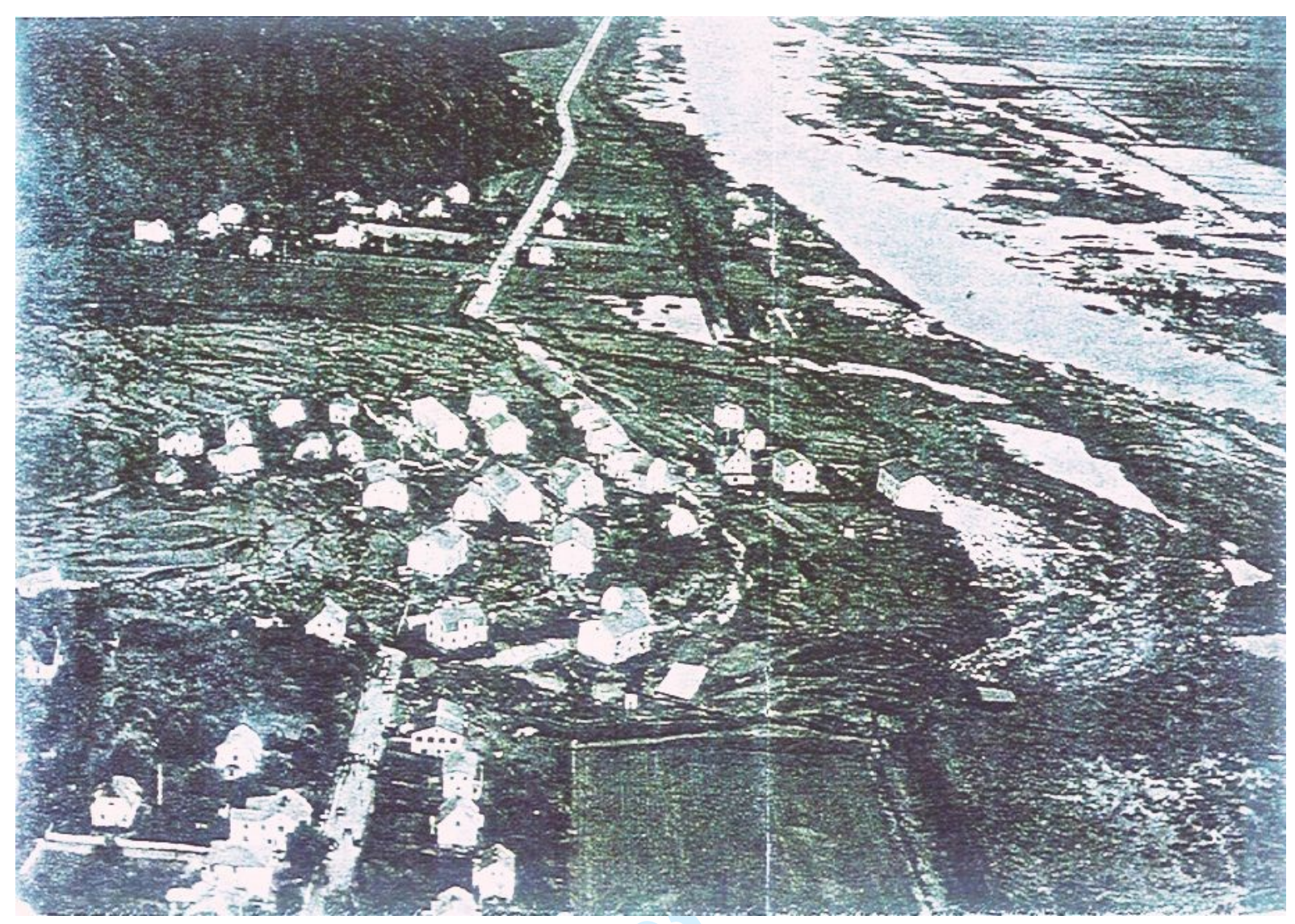

Figure 9. Aerial view of the Surte landslide in the valley of the Göta River some $10 \mathrm{~km}$ North of the city of Gothenburg, Sweden. From North looking South 


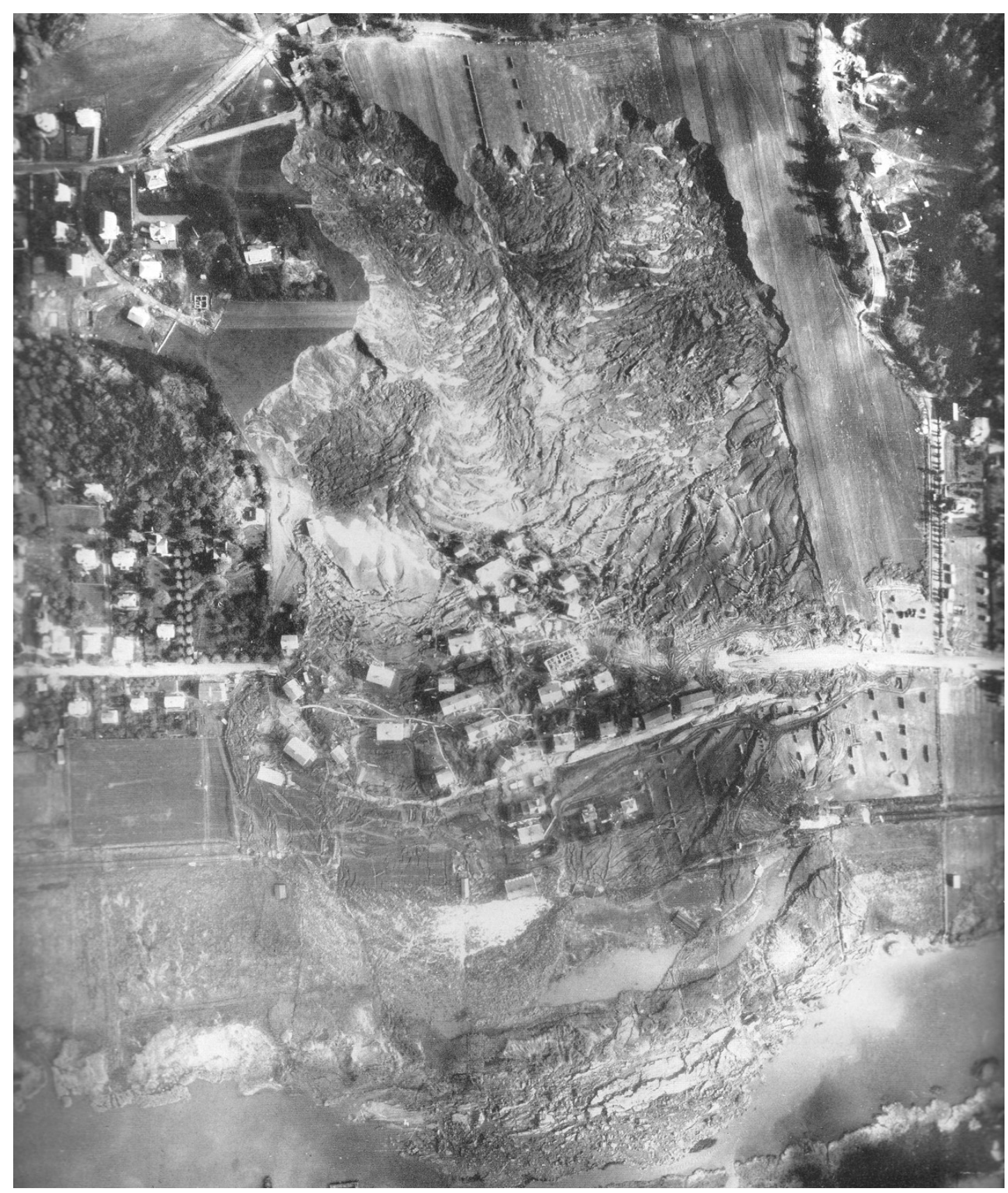

Figure 10. Aerial photograph taken 13 days after the Surte slide. From Caldenius and Lundström (1956). 

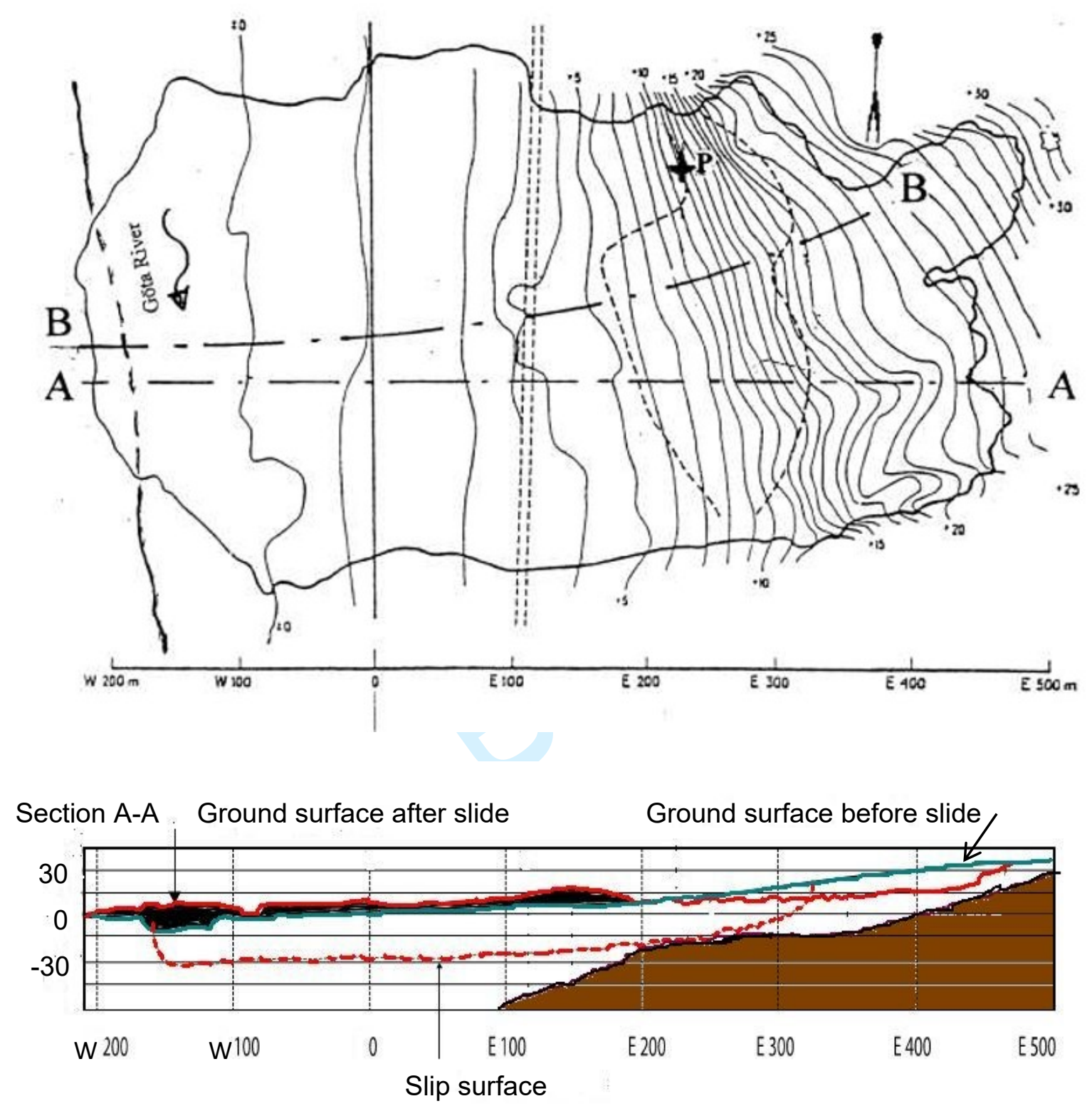

Figure 11. Plan of the Surte slide area showing elevation contours and a longitudinal section A-A of the slide. The point marked $(\mathrm{P})$ on the plan is the location in the steepest portion of the slope, where piling operations were going on at the time of the slide occurrence. Section B-B marks the section being analysed in Figure 13. 


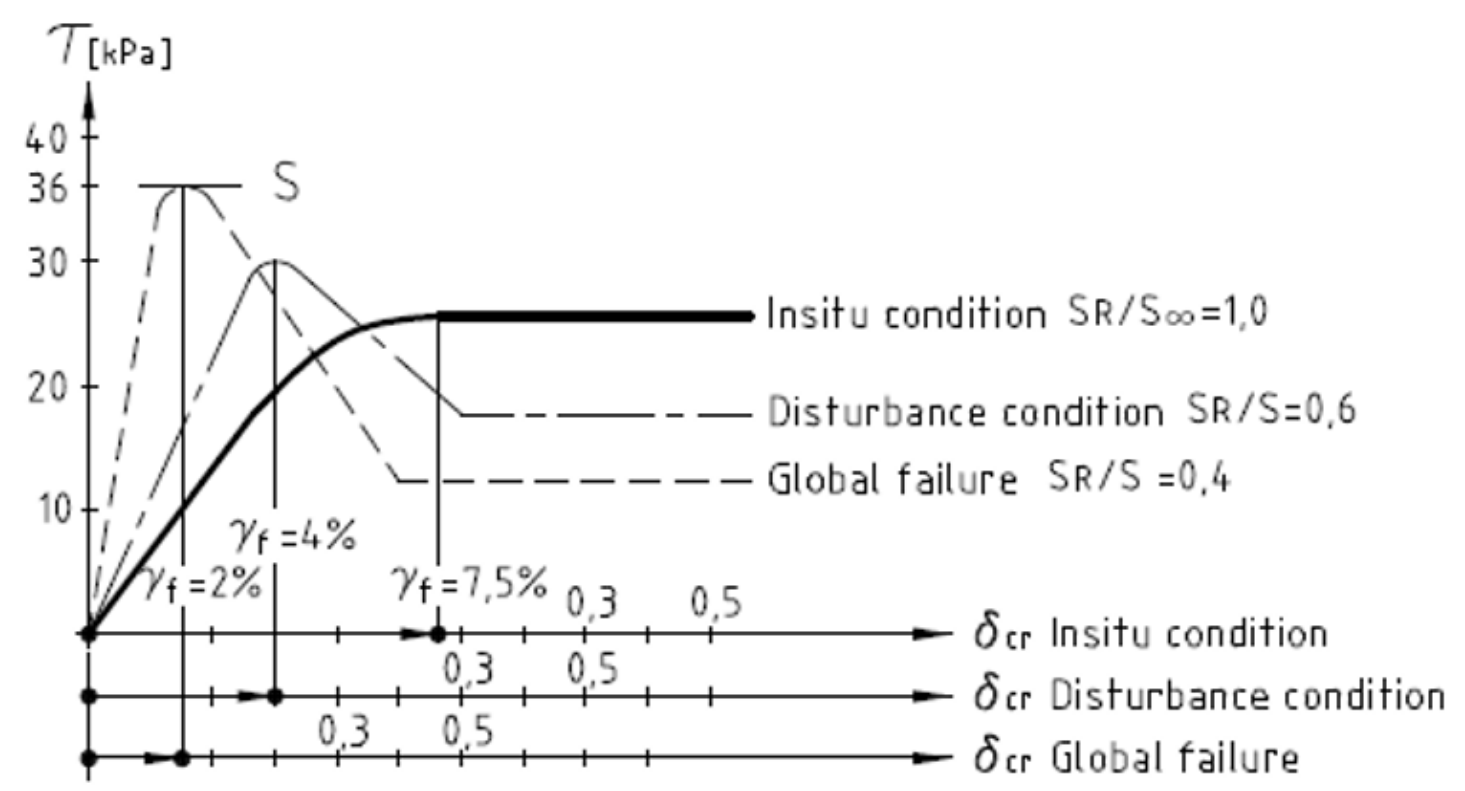

Figure 12 Stress-deformation relationships for different phases of a slide: In situ (Phase 1), Disturbance (Phase 2) and Global failure (Phase 4 and 5). See also Table 1. 


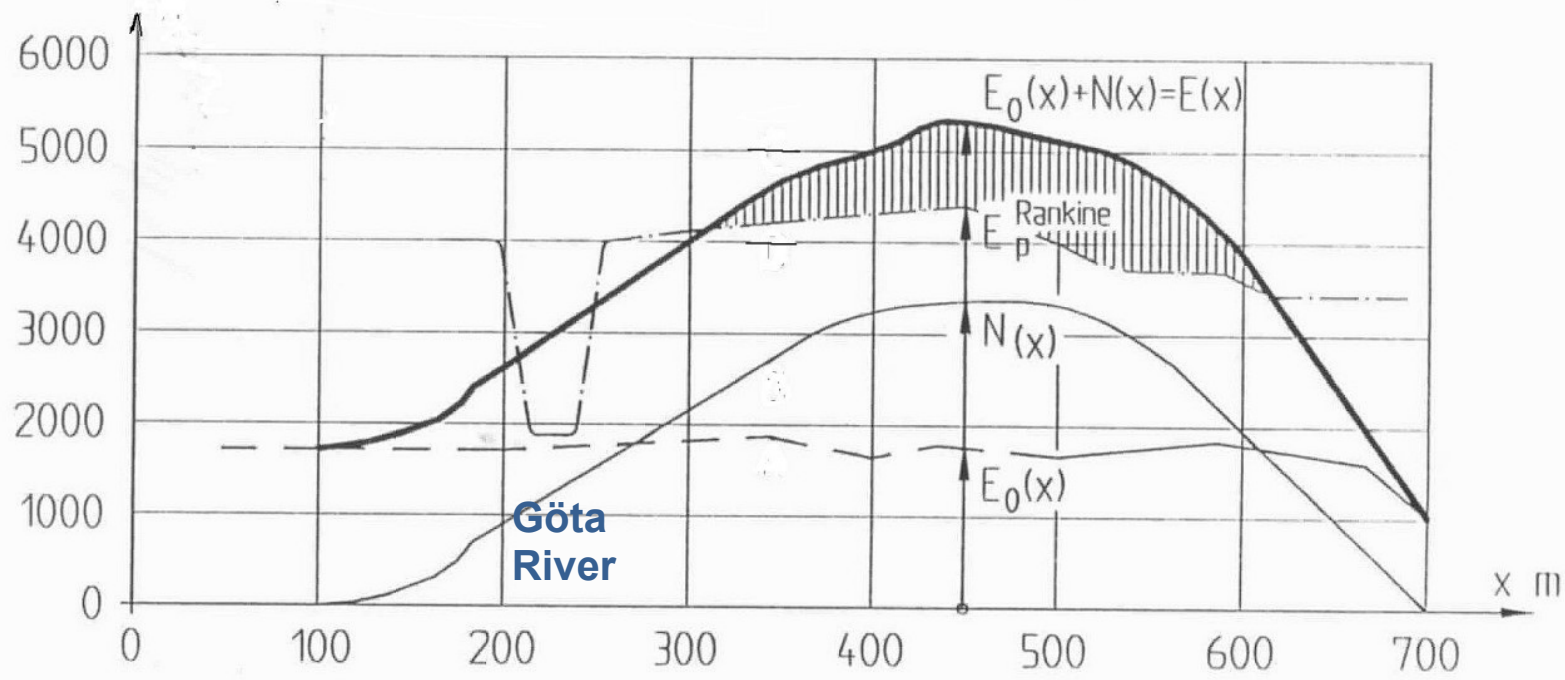

Displacement

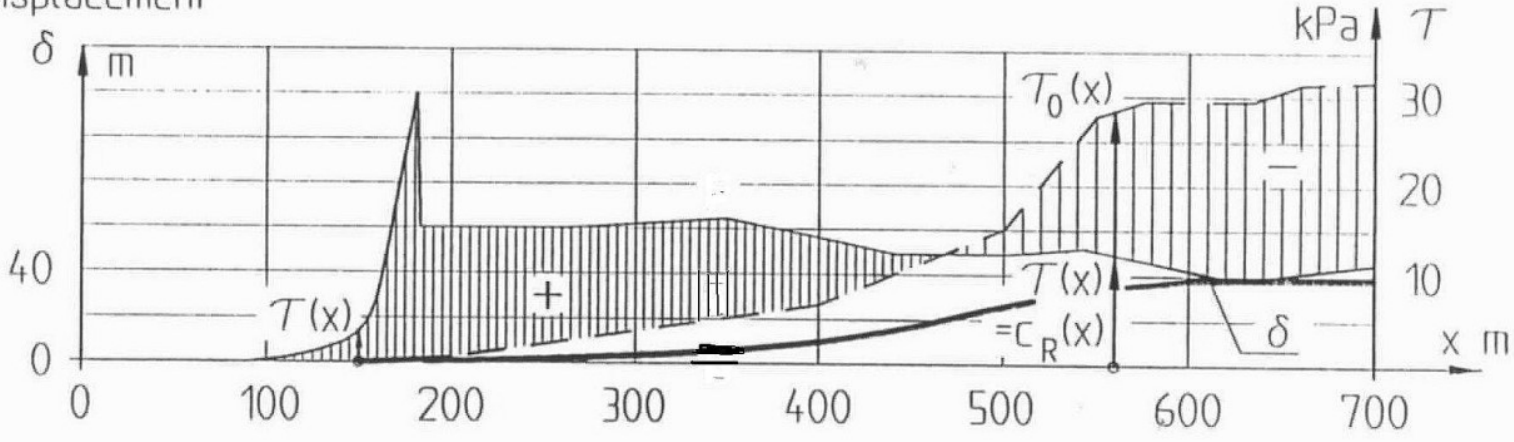

Elevation

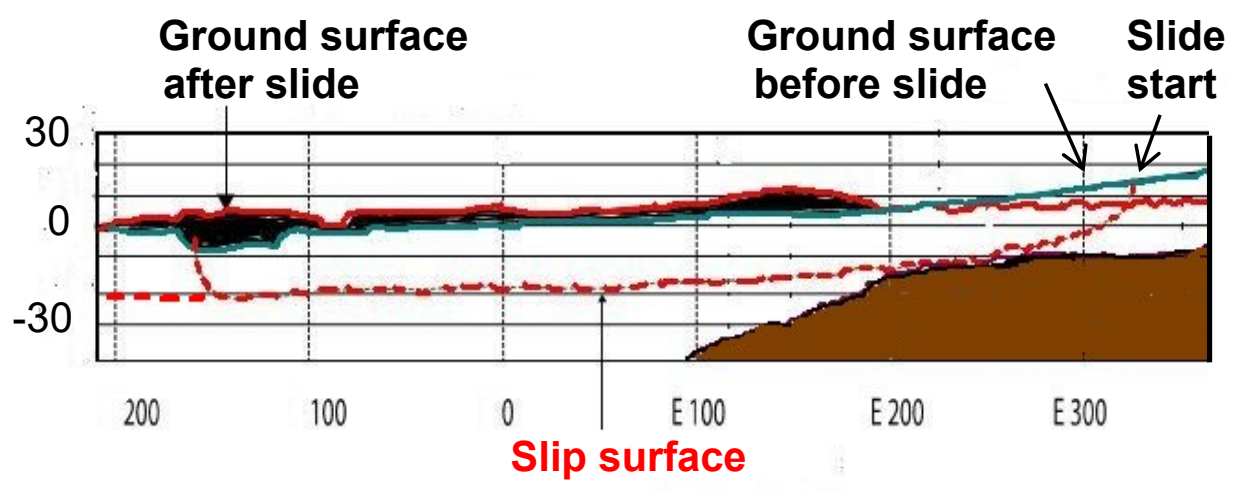

$E_{o}(x)+N(x)=E(x)=$ Earth pressure after redistribution, (Phase 4), $\mathrm{kN} / \mathrm{m}$ $E_{P}$ Rankine $=$ Passive Rankine resistance, $\mathrm{kN} / \mathrm{m}$

$N(x)=$ Earth pressure increment due to disturbance, (Phase 2), $\mathrm{kN} / \mathrm{m}$

$E_{o}(x)=$ In situ earth pressure prior to local failure, $\mathrm{kN} / \mathrm{m}$

$\tau_{o}(x)=$ In situ shear stress distribution before progressive failure, $\mathrm{kN} / \mathrm{m}^{2}$

$\tau(x)=$ Shear stress distribution after progressive failure (Phase 4 ), $\mathrm{kN} / \mathrm{m}^{2}$

$\delta(x)=$ Displacement, $m$ 
Figure 13. Static earth pressure distribution in the Surte slide in Phase 4 subsequent to the progressive failure phase (Phase 3 ) but prior to the slide proper resulting in disintegration and heave in a state of passive failure (Phase 5). The figure indicates that the static forces developed in the progressive phase of the ground movement suffice to explain the passive spread of the passive zone over almost horizontal ground. 


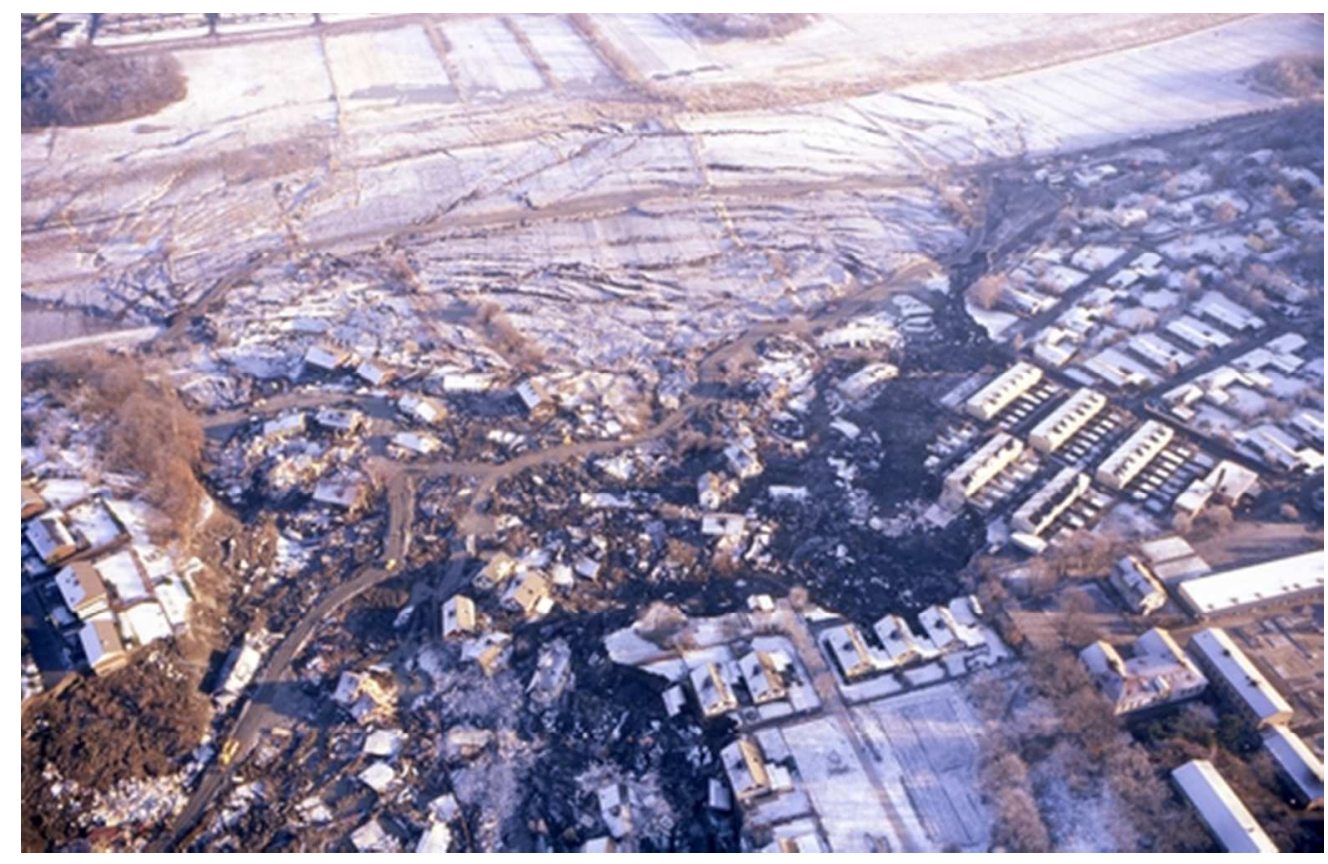

Figure 14. Aerial photograph of the Tuve slide with East in the top. Copyright Gothenburg Museum of Natural History.

$21 \times 14 \mathrm{~mm}(600 \times 600 \mathrm{DPI})$ 


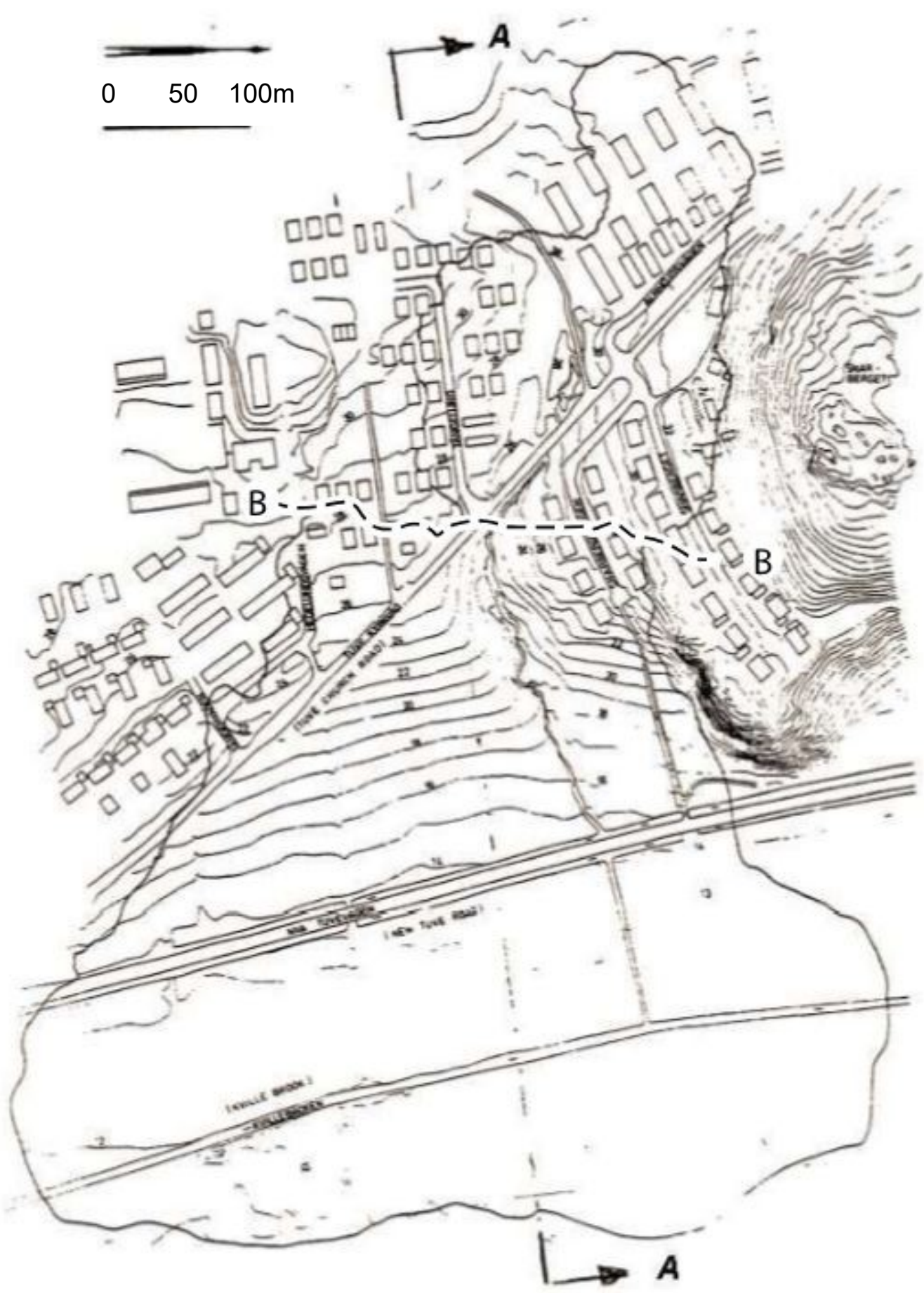

Figure 15. The landslide at Tuve, 1977. Topography of the valley before the slide and boundaries of the slide area. Results of the analysis of the initial downhill slide, i.e. below boundary B-B, are shown in Figure 16. Bernander (2011). 

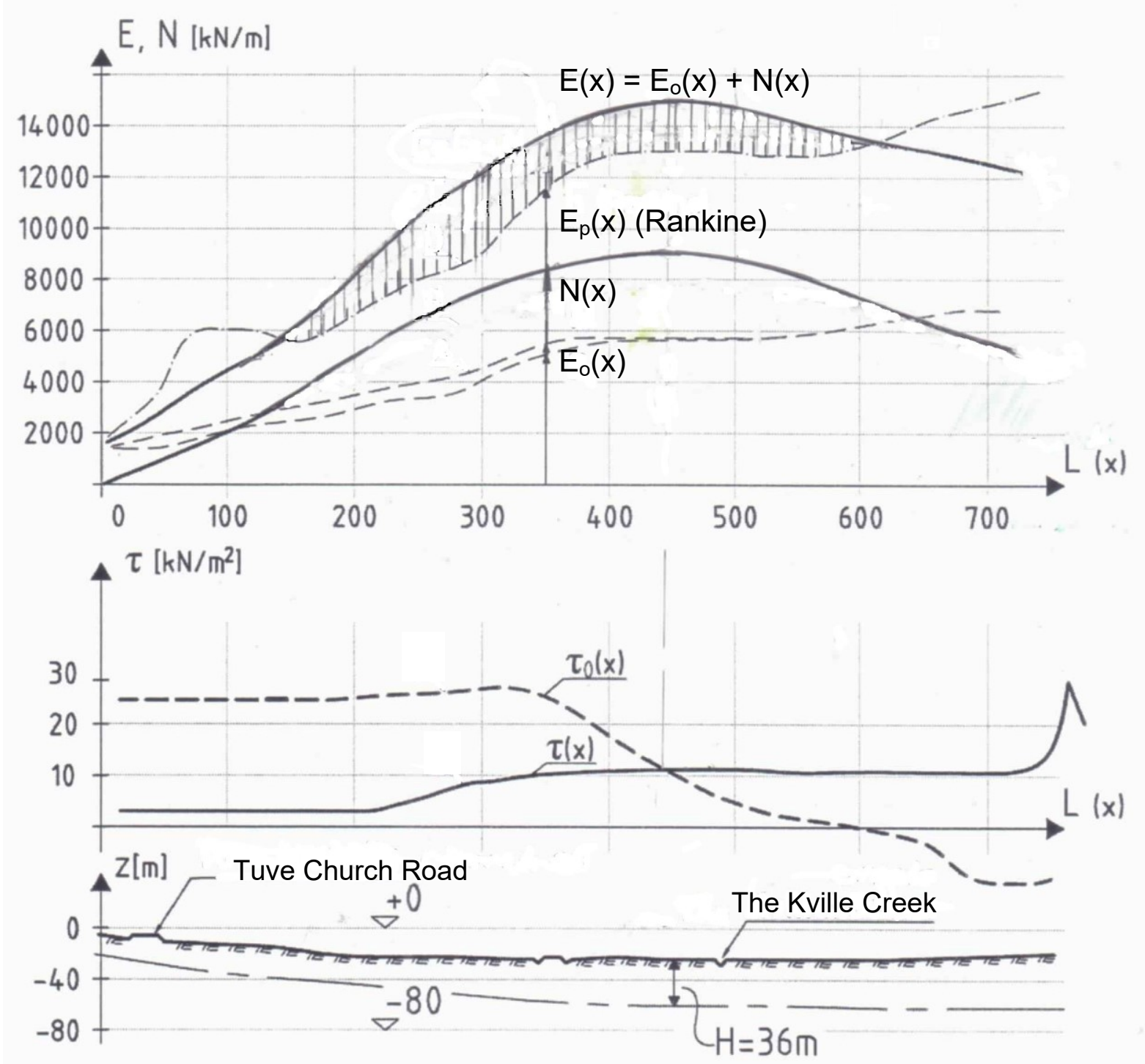

$E(x)=E_{0}(x)+N(x)=$ Earth pressure, $\mathrm{kN} / \mathrm{m}$

$E_{\mathrm{p}}(\mathrm{x})=$ Passive Rankine resistance, $\mathrm{kN} / \mathrm{m}$

$N(x)=$ Earth pressure increment, $\mathrm{kN} / \mathrm{m}$ (Phase 2)

$E_{o}(x)=$ In situ earth pressure prior to local failure, $\mathrm{kN} / \mathrm{m}$ (two curves)

$\tau_{0}(x)=$ In situ shear stress distribution before progressive failure, $\mathrm{kN} / \mathrm{m}^{2}$

$\tau(x)=$ Shear stress distribution after progressive failure, $\mathrm{kN} / \mathrm{m}^{2}$, (Phase 4)

Figure 16. Tuve landslide. Static earth pressure distribution (top), shear stresses (middle) and elevation (bottom), subsequent to the progressive failure phase but prior to the slide proper resulting in disintegration and heave in passive failure, (Phase 5). A major part of the spread of the passive zone over almost horizontal ground can be ascribed to the forces developed at the end of the dynamic progressive Phase 3 of the ground movement, Bernander (2000). 


\section{Elevation}

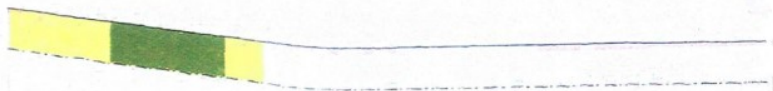

\section{Shear stresses $\tau$}

(a) Phase 3, $t=3,2 \mathrm{sec}$

\section{Elevation}

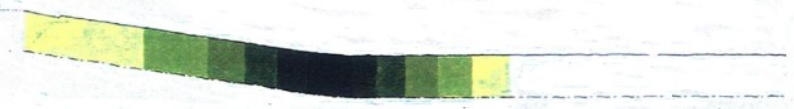

\section{Shear stresses $\tau$}

(b) Phase 4, $t=4,7 \mathrm{sec}$

\section{Elevation}

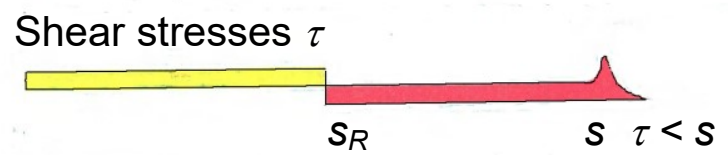

(c) Phase 5, $t=18 \mathrm{sec}$

Figure 17. Dynamic analysis illustrating elevations and shear stresses at different times from the initiation of a slide in the upper left part of the figure: (a) Phase 3, (b) Phase 4 and (c) Phase 5. In the elevations, increasing earth pressure intensities are illustrated with shades of yellow $\rightarrow$ green $\rightarrow$ dark green $\rightarrow$ black, where black indicates that passive Rankine pressure is exceeded. In the shear stress diagrams the red color indicates from right to left: increasing stresses, peak stress $s$, and softening reaching the residual stress $s_{R}$; the orange or yellow color indicates the difference between shear stresses due to forces acting downhill and the resistance $s_{R}$. Bernander and Gustås (1984), Bernander $(2000,2011)$. 


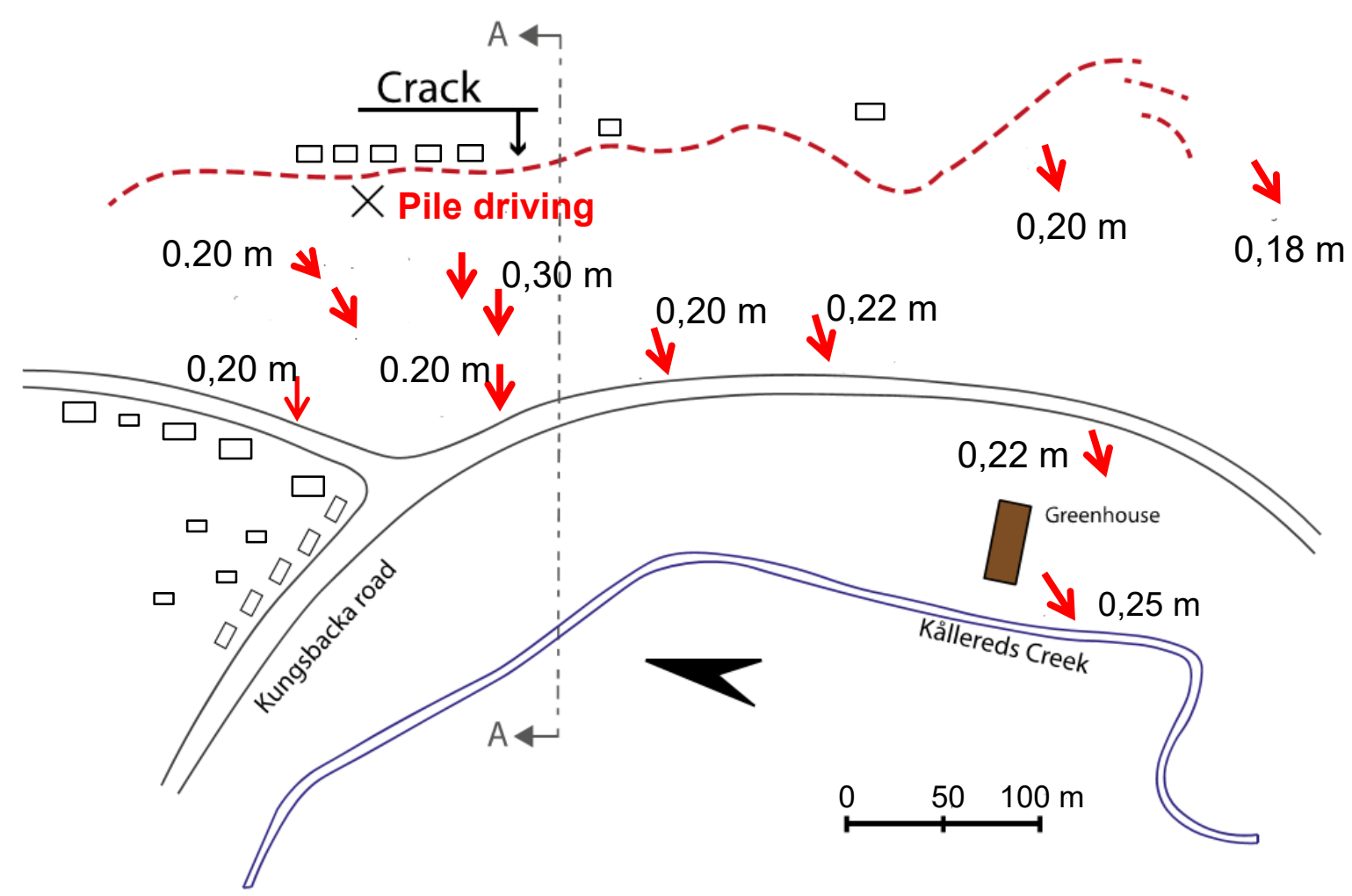

\section{Section A-A}

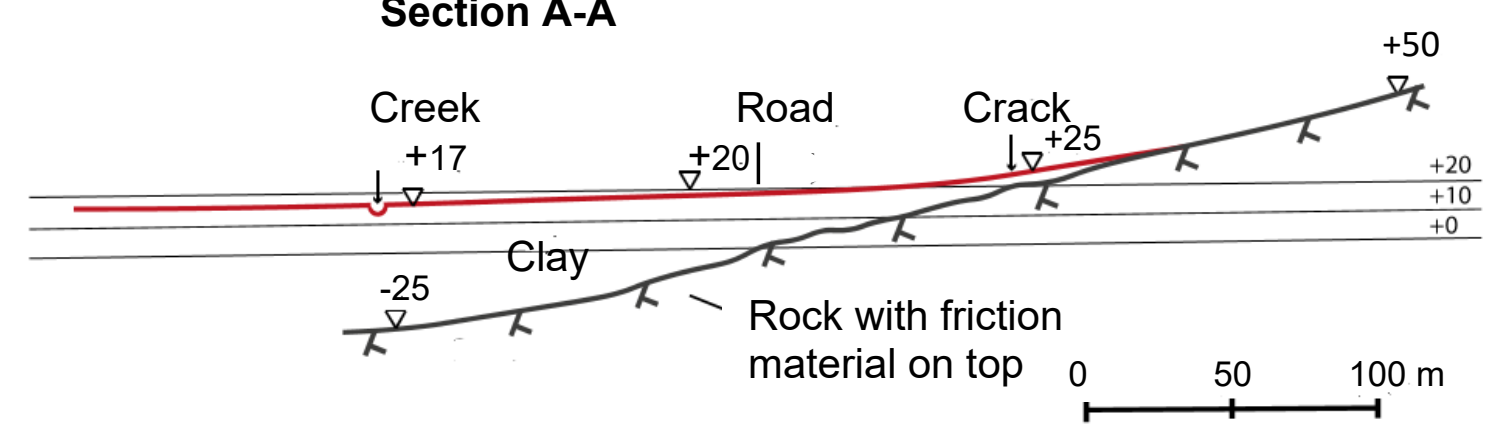

Figure 18. Plan and section through the slide area at Rävekärr. Observe the gentle slope gradient. Slip surfaces were documented at depths of 5-7 $\mathrm{m}$ in the upper part of the slide and angular deformations were recorded at $13 \mathrm{~m}$ and $33 \mathrm{~m}$ depth in the lower parts of the valley. Redrawn from Lövquist (1973). 


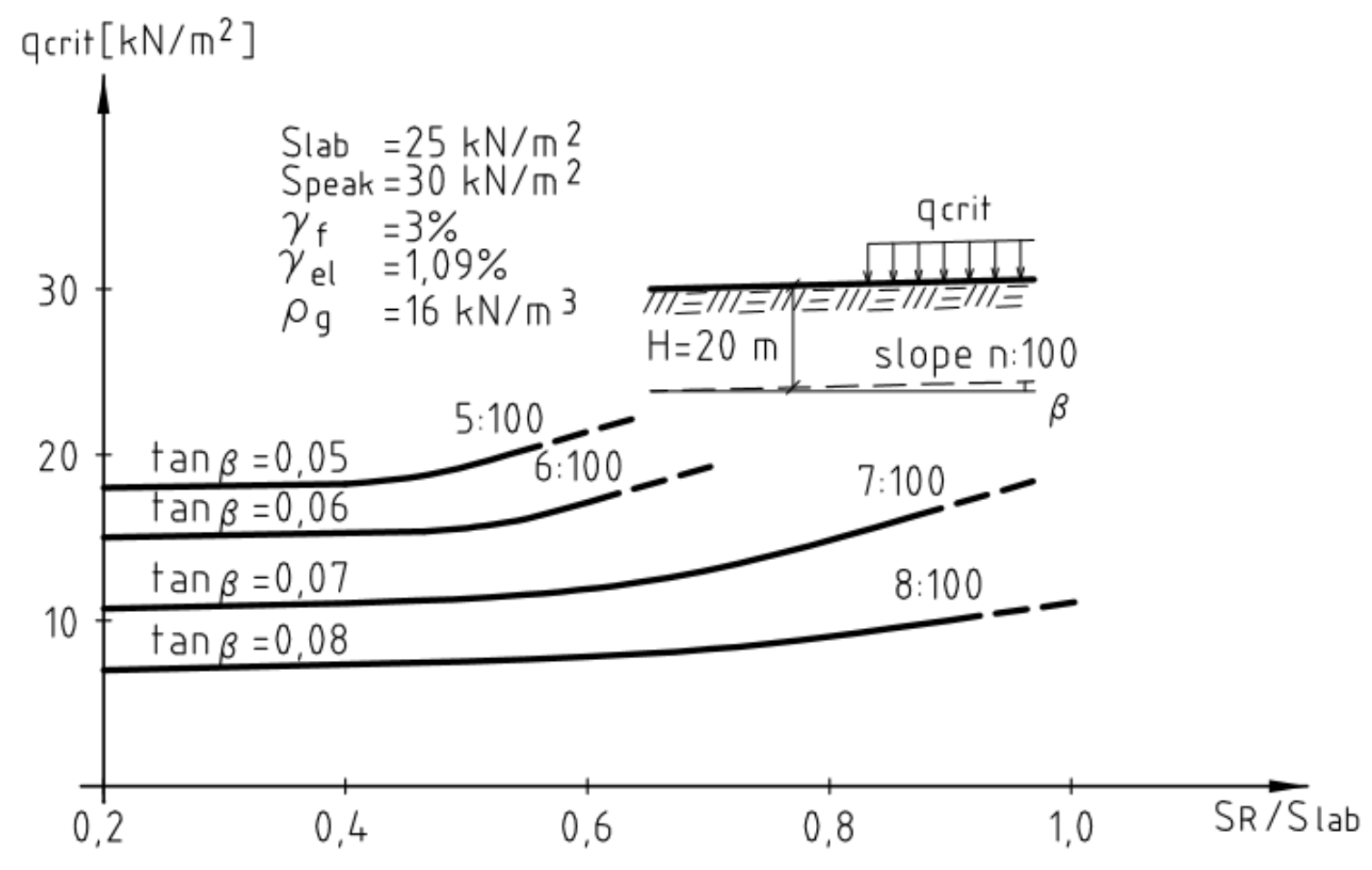

Figure 19. Critical triggering load $q_{c r i t}$ as function of slope inclination $\beta$ and residual shear resistance $s_{R} / s_{l a b}$, where $s_{R}$ is the ultimate residual stress and $s_{l a b}$ is the maximum stress obtained in laboratory tests. Bernander (2008). 